\title{
Redundancy in the central tachykinin systems safeguards puberty onset and fertility.
}

Silvia León ${ }^{1,2}$, Chrysanthi Fergani ${ }^{1,2}$, Rajae Talbi ${ }^{1,2}$, Serap Simavli ${ }^{2}$, Caroline A. Maguire ${ }^{2}$, Achi $^{1}$ Gerutshang $^{2}$, Stephanie B. Seminara ${ }^{1,3}$, Víctor M. Navarro ${ }^{1,2}$.

${ }^{1}$ Harvard Medical School, Boston, MA; ${ }^{2}$ Division of Endocrinology, Diabetes and Hypertension, Brigham and Women's Hospital, Boston MA; ${ }^{3}$ Harvard Reproductive Sciences Center and Reproductive Endocrine Unit, Massachusetts General Hospital, Boston, MA.

Corresponding authors: Víctor M. Navarro, Ph.D.

Division of Endocrinology, Diabetes and Hypertension, Department of Medicine, Brigham and Women's Hospital and Harvard Medical School, Boston, MA 02115

Email: vnavarro@bwh.harvard.edu

Keywords: Neurobiology, fertility, tachykinins, development.

Conflict of Interest: The authors have nothing to disclose. 


\begin{abstract}
The tachykinin neurokinin B (NKB, Tac2) is critical for GnRH release. NKB signaling deficiency leads to infertility in humans. However, some patients reverse this hypogonadism resembling the fertile phenotype of Tac2KO and Tacr3KO (encoding NKB receptor, NK3R) mice despite the absence of NKB signaling. Here, we demonstrate that in the absence of NKB signaling, other tachykinins (substance $P$ and neurokinin $A$ [NKA], encoded by Tac1) may take over to preserve fertility. The complete absence of tachykinins in Tac1/Tac2KO mice leads to delayed puberty onset in both sexes and infertility in $80 \%$ of females (but not males), in contrast to the $100 \%$ fertile phenotype of Tac1KO and Tac2KO mice separately. Furthermore, we demonstrate that NKA controls puberty onset and LH release through NKB-independent mechanisms in the presence of sex steroids and NKB-dependent mechanisms in their absence. In summary, tachykinins interact in a coordinated manner to ensure reproductive success in female mice.
\end{abstract}




\section{Introduction}

2

Tachykinins (TACs) are a large family of peptides that includes neurokinin A (NKA) and substance $\mathrm{P}(\mathrm{SP})$, encoded by TAC1, and neurokinin B (NKB), encoded by TAC3 (or Tac2 in rodents) (1). TACs act on different G protein-coupled receptors: NK1R (encoded by Tacr1), the receptor for SP; NK2R (Tacr2), the receptor for NKA; and NK3R (Tacr3), the receptor of NKB. These TAC systems are expressed throughout the central nervous system, where they participate in a variety of physiological functions, e.g. nociception and fear conditioning $(1,2)$.

Recently, the NKB/NK3R system has emerged as a critical neuroendocrine regulator of reproductive function. A growing body of evidence from our lab and others has documented the stimulatory role of $\mathrm{NKB}$ on $\mathrm{GnRH}$ release in an estradiol and kisspeptin dependent manner in all studied species, including the human (3).

Moreover, inactivating mutations in TAC3/TACR3 genes lead to hypogonadotropic hypogonadism $(\mathrm{HH})$ in patients, presenting delayed or absent puberty onset and infertility $(4,5)$. However, a number of human patients bearing these mutations overcome initial pubertal failure and central hypogonadism, with a later 'awakening' of GnRH secretion and hypogonadism reversal (6); a phenotype that resembles that of Tac2KO and Tacr3KO mice, which are sub-fertile $(7,8)$. The underlying mechanism responsible for the reversal phenotype of these patients remains unknown. In addition to NKB, the SP/NK1R system also participates in the central regulation of the gonadotropic axis, likely via kisspeptin-dependent mechanisms (9, 10). Supporting this contention, (a) studies in humans, rabbits and rats showed a central stimulatory role of SP on LH release (11-13); (b) Kiss1 neurons are activated by SP (9); (c) SP mRNA and protein has been found in the ARC of rodents $(10,14) ;(d)$ SP immunoreactivity has been detected in Kiss 1 and NKB neurons in the human infundibular nucleus (15); (e) chronic SP administration advances puberty onset in rodents (16) and (f) Tac1KO mice with congenital absence of SP, display delayed puberty onset and reproductive impairments $(16,17)$.

Interestingly, because Tac1 encodes both SP and NKA we cannot rule out that the reproductive phenotype observed in Tac1KO mice (delayed puberty onset and sub-fertility) $(16,17)$ is not, at 
29 least in part, due to the absence of NKA signaling, whose participation in the control of puberty

30 onset and fertility remains largely unknown. We and others have documented that NKA also

31 induces LH release in rodents $(10,18,19)$ in a kisspeptin-dependent manner $(10)$. Interestingly,

32 the stimulatory action of NKA on LH release is dependent on the presence of physiological levels

33 of circulating sex steroids, while in their absence, NKA inhibits LH release, similar to NKB (10).

34 However, unlike NKB, NKA's receptor (NK2R) is not present on Kiss1 or GnRH neurons (10). We

35 therefore hypothesize that NKA must act upstream of Kiss1 neurons, on an unknown population

36 of neurons, that in turn control NKB release. Alternatively, all TAC ligand-receptor systems have

37 been reported to display cross-reactivity (20), implicating that cross-activation of NK3R by NKA

38 could be an explanation for the NKB-like action of NKA. Overall, there is compelling evidence that

39 all TACs (not only NKB) participate in the control of $\mathrm{GnRH}$ release. This highlights the importance

40 of deciphering the mechanism of action for each one individually, as well as in combination with

41 other tachykinins, in order to better understand their role in the neuroendocrine control of

42 reproduction.

$44 \quad$ Results

\section{Complete absence of tachykinins in double Tac1/Tac2 $\mathrm{KO}$ females severely disrupts}

\section{7 puberty onset and fertility in females.}

48 In order to test our hypothesis, that there is redundancy in the tachykinin systems that preserves

49 fertility in the absence of NKA/SP signaling (Tac1KO mice) or NKB signaling (Tac2KO and

50 Tacr3KO mice) individually $(7,8,16)$, we generated double Tac1/Tac2 KO mice and compared

51 their reproductive maturation and fertility to their single mutant littermates. Interestingly, while

52 Tac1 $\mathrm{KO}$ and Tac2KO mice displayed delayed VO, as reported previously, double Tac1/Tac2 KO

53 females presented only a moderate (not significant) delay in VO compared to WT littermates

54 (Figure $1 \mathrm{~A}-\mathrm{C}$ ), however, they failed to show any signs of first estrous for over 30 days post VO

55 (Figure 1 D). Of note, first estrous is a more accurate marker of puberty onset as it indicates

56 central activation of the gonadotropic axis. Furthermore, in a fertility test in which adult females 
57 were mated with proven fertile WT males, only $20 \%$ of Tac1/Tac2 KO females were able to deliver

58 pups over a 90-day long period of mating (Figure 1 E). Moreover, the parturition latency of these

59 small portion of Tac1/Tac2 KO females was longer than in WT controls (WT: $21.66 \pm 0.66$ days;

60 Tac1/Tac2 KO: $29.5 \pm 0.5$ days; ${ }^{* *} \mathrm{p}<0.01$ ) (Figure $1 \mathrm{~F}$ ) and the litter size was significantly smaller

61 than in controls (WT: $7.33 \pm 1.08$ pups; Tac1/Tac2 KO: $4 \pm 0$ pups; ${ }^{* *} p<0.01$ ) (Figure 1 G). This

62 largely infertile phenotype of Tac1/Tac2 $\mathrm{KO}$ females is also supported by the reduced number of

63 corpora lutea in their ovaries (WT: $3.5 \pm 0.28 \mathrm{CL} /$ ovary; Tac1/Tac2 KO: $0.75 \pm 0.25$ CL/ovary;

$\left.64^{* * *} p<0.001\right)($ Figure $1 \mathrm{H}, \mathrm{I})$ and significantly lower ovarian weight than controls (WT: $18.50 \pm 1.70$

$65 \mathrm{mg} ;$ Tac1/Tac2 KO: $\left.10.83 \pm 1.63 \mathrm{mg} ;{ }^{* *} \mathrm{p}<0.01\right)$. Moreover, since previous studies had

66 documented an improvement of estrous cyclicity with age in Tac2KO mice (8), we assessed

67 whether this was also the case in Tac1/Tac2 KO females at a young (3 months) and older (8

68 months) age and observed that, in both cases, KO females failed to show any signs of regular

69 estrous cyclicity (Figure $1 \mathrm{~J}, \mathrm{~K})$.

\section{Tac1/Tac2 KO females display disrupted LH pulses and response to ovariectomy.}

72 To further characterize the reproductive phenotype of Tac1/Tac2 KO females, LH pulsatility and

73 long-term response to OVX were assessed. As expected, OVX Tac1/Tac2 KO females displayed

74 a severely disrupted LH pulse pattern (fewer pulses) over 150 minutes compared to OVX WT

75 (WT: $3.33 \pm 0.56$ pulses/150min; Tac1/Tac2 KO: $1.86 \pm 0.26$ pulses/150min; * $p<0.05$ ) (Figure 2

76 A-C). Interestingly, when the response of LH to OVX was assessed, we observed a biphasic

77 response in which $\mathrm{LH}$ levels were reduced compared to WT in Tac1/Tac2 KO and Tac2KO

78 females 2 days post OVX; however, there was a quick rebound that led to normal LH levels in

79 both KO models compared to WT females at 7 days post OVX (Figure 2 D). Next, we aimed to

80 assess the ability of Tac1KO, Tac2KO and Tac1/Tac2 $\mathrm{KO}$ females to respond to the central

81 administration of kisspeptin (Kp-10) and $\mathrm{GnRH}$. As we previously reported, the lack of Tac1 led

82 to a diminished LH response to $\mathrm{Kp}-10$ (17), which was replicated in Tac1/Tac2 KO females and 
83 extended to the $\mathrm{GnRH}$ response (Figure $2 \mathbf{E}, \mathbf{F}$ ), while the expression of the tachykinin receptors

84 (Tacr1, Tacr2 and Tacr3), Kiss1 and Pdyn remained unaffected (Figure 2 G, H).

3. Complete absence of tachykinins in double Tac1/Tac2 KO males delays puberty onset

87 but does not affect fertility.

88 Similar to the delay in first estrus in female Tac1/Tac2 KO mice, males displayed delayed puberty

89 onset as shown by the timing of preputial separation (Figure 3 A-C). However, and unlike

90 females, Tac1/Tac2 KO males were fertile, with a 100\% success ratio in their ability to impregnate

91 WT females (Figure 3 D-F). Concordantly, their testicular histology was normal compared to

92 controls, showing mature sperm in all cases (Figure $\mathbf{3}$ G) and normal testicular weight (WT 163.31

$93 \pm 6.38 \mathrm{mg} ;$ Tac1/Tac2 KO $172.84 \pm 9.20 \mathrm{mg}$ ). As in females, Tac1/Tac2 $\mathrm{KO}$ males presented a

94 delay in the response to gonadectomy 2 days after surgery, however, LH levels returned to normal

95 by 7d post GDX (Figure $3 \mathrm{H}$ ). Finally, similar to our previous reports in Tac1KO males (17) and to

96 our present data in females (Figure 2), Tac1/Tac2 KO males have a significant decrease in the

97 response to $\mathrm{Kp}-10$ and $\mathrm{GnRH}$ (Figure $3 \mathbf{I}, \mathbf{J})$.

\section{The receptor of NKA (NK2R) is expressed in VMH Tac1 neurons.}

100 Our previous studies have documented the existence of mRNA of the NKB receptor (NK3R) and 101 SP receptor (NK1R) in $\sim 100 \%$ and $\sim 50 \%$, respectively, of Kiss1 neurons in the ARC, while the 102 receptor of NKA (NK2R) was undetectable in Kiss1 or GnRH neurons (10). We therefore aimed 103 to assess if NK2R (encoded by Tacr2) is expressed in other ARC neurons or in its nearby $\mathrm{VMH}$ 104 nucleus and whether it colocalizes with Tac1 neurons in these areas, as a critical source of SP and NKA in the control of kisspeptin/GnRH release. Our in situ hybridization (RNAscope) results showed that Tacr2 is expressed in both ARC and VMH nuclei and colocalizes with Tac1 neurons

107 in the VMH of adult WT mice regardless of the E2 milieu (Figure 4). 
110 Figures 1 and 3 evidenced that tachykinins are needed for normal timing of puberty onset in male

111 and female mice. Likewise, our previous studies have demonstrated that chronic administration

112 of specific agonists of the NK1R and NK3R receptor are able to advance puberty onset in rodents

$113(16,21)$, indicating that these systems are in place before puberty and likely participate in the

114 proper timing of puberty onset. However, whether NKA/NK2R is also involved in the re-awakening

115 of the gonadotropic axis at the time of puberty is unknown. To address this question, we

116 chronically (every 12h) treated WT females with a specific agonist of NK2R from weaning age

117 (22d) to $32 \mathrm{~d}$. We observed that this treatment was able to advance puberty onset as evidenced

118 by the advanced timing of $\mathrm{VO}$ and increased uterus and ovarian weight compared to controls

119 (Uterus weight: Control: $19.55 \pm 1.89 \mathrm{mg}$; NK2R-Ag treated: $23.79 \pm 1.61 \mathrm{mg}$; $\mathrm{p}<$ < 0.05. Ovarian

120 weight: Control: $8.3 \pm 0.56 \mathrm{mg}$; NK2R-Ag treated: $\left.11.7 \pm 0.44 \mathrm{mg} ;{ }^{* *} \mathrm{p}<0.001\right)$ (Figure 5 A-F).

\section{The stimulatory action of NKA is independent of NKB but dependent of kisspeptin.}

123 We previously reported that NKA and NKB action on LH release is largely equivalent, i.e. both

124 increase $\mathrm{LH}$ release in the presence of physiological circulating levels of $\mathrm{E}_{2}$ but inhibit $\mathrm{LH}$ in the 125 absence of sex steroids (10). It was therefore tentative to speculate that NKA could induce LH 126 release through the stimulation of NKB given the absence of NK2R in Kiss1 and GnRH neurons.

127 To test this hypothesis, first we co-administered NK2R and NK3R agonists to OVX $+\mathrm{E}_{2}$ WT mice 128 and observed that the increase in LH was similar in groups injected with an individual dose of 129 each agonist or the combination of both (Figure 6 A), discarding the possibility of an additive 130 effect of NKA and NKB action on LH release and suggesting a possible common pathway. Next, 131 to evaluate if NKA requires NKB signaling to induce $\mathrm{LH}$ release, the $\mathrm{LH}$ response to NK2R-Ag 132 was tested in the presence of an NK3R antagonist (Figure 6 B) and in NKB deficient (Tac2KO) 133 mice (Figure 6 C). In both cases, NK2R-Ag was able to significantly stimulate LH release 134 indicating that NK2R activation induces LH release independently of the presence of NKB or its receptor NK3R. However, NK2R signaling requires the presence of kisspeptin as Kiss1KO mice 
137 NK2R-Ag: $0.57 \pm 0.09$ ng/mL; * $<$ <0.05; Kiss1KO Basal: $0.21 \pm 0.02$ ng/mL, Kiss1KO NK2R-Ag:

$0.29 \pm 0.04 \mathrm{ng} / \mathrm{mL}$; not significant)

\section{The inhibitory action of NKA is NKB and dynorphin dependent.}

141 In the next set of experiments, we sought to determine whether the inhibitory action of NKA/NK2R

142 on LH release in the absence of sex steroids (i.e. OVX) is mediated by NKB and dynorphin. First,

143 we showed that the inhibitory action of NK2R-Ag + senktide was similar to that of senktide alone,

144 suggesting (as in the presence of $E_{2}$ ) that there is no additive effect of both tachykinins in the

145 inhibition of LH (Figure 7 A). The use of the specific NK3R antagonist already decreased LH in

146 OVX animals, in line with recent literature showing that blockade of NK3R decreases LH pulsatility

147 (22-25); however, co-administration of the NK3R antagonist and the NK2R-Ag failed to induce a

148 further decrease in LH, suggesting that NK3R signaling is required for the inhibitory action of NKA

149 in the absence of $\mathrm{E}_{2}$ (Figure $7 \mathrm{~B}$ ). Moreover, as previously described in rats, NK2R signaling

150 requires dynorphin to inhibit LH (26), which is abolished after the blockade of the kappa and mu

151 receptor, KOR and MOR respectively, using naloxone (Figure 7 C). Of note, naloxone alone also

152 inhibited LH release in OVX mice, in line with our previous reports in OVX PdynKO and Oprk1KO

153 mice (dynorphin KO and KOR KO mice, respectively) (27), suggesting that the absence of the

154 inhibitory signal of dynorphin leads to a significant decrease in the ability of the mouse to secrete

$155 \mathrm{LH}$, probably due to disruption of the LH pulse generator mechanism (28). Next, we assessed the

156 action of NK2R-Ag in the absence of NKB (Tac2KO mice) to further confirm the data obtained

157 after NK3R blockade. Unexpectedly, we observed that the absence of NKB leads to a robust

158 induction of LH release, uncovering an action that is not present in WT OVX regardless of whether

159 a functional NK3R is present or antagonized.

161 Because we have observed that VMH Tac1 neurons co-express Tacr2 (NK2R) (Figure 4), we 162 hypothesized that NKA could also induce LH release through the stimulation of SP from Tac1 163 neurons that, in turn, would activate Kiss1 neurons (10). To test this hypothesis, we administered 
164 the NK2R-Ag in the presence of a NK1R antagonist (proven to efficiently block the action of a

165 NK1R- agonist (Figure 7, E)) in WT and Tac2KO OVX mice. In both cases, NK2R-Ag was able

166 to replicate the effect seen in WT (inhibition of LH, Figure $7 \mathbf{E}$ ) and Tac2KO mice (stimulation of

167 LH, Figure 7 F). Lastly, we confirmed that this action is kisspeptin-dependent by showing 168 complete absence of LH response to the administration of NK2R-Ag in Kiss1 KO mice (WT: Basal $2,90 \pm 0.42 \mathrm{ng} / \mathrm{mL}, \mathrm{NK} 1 \mathrm{R}-A g 2.08 \pm 0.32 \mathrm{ng} / \mathrm{mL},{ }^{*} \mathrm{p}<0.05 ;$ Kiss1KO: Basal $0.32 \pm 0.06 \mathrm{ng} / \mathrm{mL}$ NK1R-Ag $0.30 \pm 0.02 \mathrm{ng} / \mathrm{mL}$, not significant).

\section{Discussion}

173 In the present study, we show that all tachykinins are essential for the normal timing of puberty 174 onset in both sexes and critical for the maintenance of fertility in females. Humans and mice with 175 deficient NKB/NK3R signaling present delayed puberty onset $(4,5,7,8)$. We have also described previously that SP is critical for the proper timing of puberty onset in the mouse $(16,17)$ and here we extend that finding to include NKA as well.

179 The reproductive phenotype of TAC3/TACR3 deficient patients (without NKB/NK3R signaling) has spurred controversy as their infertile phenotype has been shown to reverse spontaneously in some patients leading to successful pregnancies (6). This phenotype resembled the fertile phenotype of both Tac2 and Tacr3 KO mice $(7,8)$. The current model of NKB's action proposes that NKB plays a role before puberty by stimulating the release of kisspeptin (29) and that after puberty it participates in the shaping of kisspeptin-GnRH-LH pulses as part of the GnRH pulse generator within the arcuate/infundibular nucleus (30). Therefore, the explanation for the reversal of the $\mathrm{HH}$ phenotype in patients and mice without this seemingly critical factor for $\mathrm{GnRH}$ pulsatility

187 remained unknown and demanded further investigation. Because tachykinins have been 188 described to cross-activate all three NK receptors $(31,32)$, we hypothesized that in the absence 189 of NKB signaling, SP and/or NKA could compensate for the role of NKB and eventually be able 
190 to activate the gonadotropic axis. Our present results support this hypothesis, as the complete

191 absence of all tachykinins in double Tac1/Tac2 KO mice 1) recapitulates the delay in puberty

192 onset observed in NKA/SP and NKB null models $(8,16)$, and 2) leads to severe reproductive

193 defects ( $80 \%$ of infertile mice) in females in striking difference with the reproductive phenotype of

194 each studied tachykinin KO model separately (i.e. Tac1KO, Tac2KO and Tacr3KO), which

195 displayed $100 \%$ of successful pregnancies in all cases $(7,8,16)$. However, although Tac1/Tac2

196 KO males presented delayed puberty onset, as documented previously for Tac1KO mice (17), all

197 of them were able to father litters. The sex difference in the fertility phenotype is remarkable and

198 points to the fact that tachykinins may be important for the timing of puberty onset in both sexes

199 and proper pulsatile release of LH in adult females, while additional (yet unknown) mechanisms

200 are able to maintain proper activation of the gonadotropic axis in adult males. It is also possible

201 that in the female, tachykinins act at the level of Kiss1 neurons in the anteroventral periventricular

202 nucleus (AVPV/PeN), exclusive to the female brain and involved in the positive feedback of sex

203 steroids that leads to ovulation (33). In that case, the absence of tachykinin action in these

204 neurons could prevent them from mounting a proper ovulatory response, as suggested by their

205 lack of corpora lutea and almost complete infertility of Tac1/Tac2 KO females in this study, leading

206 to the sexual differentiation in the infertile vs. fertile phenotype of females and males, respectively.

207 Supporting this contention, we have previously described that a fraction of Kiss 1 neurons in the

208 ARC and AVPV/PeN express NK1R and NK3R mRNA, but not NK2R (10). In this study, we show

209 that the NK2R transcript (Tacr2) is present in additional (unknown) neurons of the ARC and in

210 Tac1 neurons of the $\mathrm{VMH}$, suggesting the existence of autosynaptic loops in these neurons similar

211 to NKB's action in ARC Kiss1 neurons, which could serve as an indirect mechanism to modulate

212 Kiss1 neurons through the regulation of SP release.

214 Our present findings also demonstrate that TACs are involved in the rapid response of Kiss1

215 neurons to the absence of negative feedback, i.e. increase in LH release after gonadectomy.

216 Tachykinin deficient mice (i.e. Tac1/Tac2 KO) showed a significant delay in the post-gonadectomy 
217 rise of $\mathrm{LH}$ levels $48 \mathrm{~h}$ after surgery. However, LH levels are restored to normal values by $7 \mathrm{~d}$ post-

218 surgery, indicating that tachykinins are not necessary for the activation of Kiss 1 neurons in the

219 mid-long term but contribute to the rapid response of the animal to changes in the sex steroid

220 milieu. Interestingly, in both sexes, the acute administration of kisspeptin or GnRH led to a

221 diminished response of LH in Tac1KO mice (as we described previously in male mice (17)) and

222 in double Tac1/Tac2KO mice. While this may reflect a defect at the level of the pituitary, both

223 genotypes were able to reach normal compensatory rises of LH after gonadectomy, as indicated

224 above, supporting the ability to mount a proper kisspeptin-GnRH-LH response and the presence

225 of normal gonadotrope function. This is in line with the delay in the response to GDX described

226 above, indicating the difficulty of these animals to mount a rapid response to $\mathrm{GnRH}$ and

227 suggesting that substance $\mathrm{P}$ may facilitate the rapid response of gonadotropes to $\mathrm{GnRH}$ at the

228 pituitary level, in agreement with previous in vitro studies (34-37).

230 In this study we also addressed the question of whether the analogous action of NKA and NKB

231 in the regulation of $\mathrm{LH}$ release (i.e. stimulation in the presence of $E_{2}$ and inhibition in its absence

$232(10))$ is due to a converging mechanism of action of NKA onto NKB signaling. Despite these

233 similarities, our data using NK3R antagonists and Tac2KO mice after OVX and $\mathrm{E}_{2}$ replacement,

234 clearly demonstrate that the stimulatory action of NKA on LH is NKB independent but kisspeptin-

235 dependent, suggesting the existence of a yet unknown population of NKA-responsive neurons

236 that in turn activate Kiss1 neurons to induce kisspeptin/GnRH release. On the contrary, NKA had

237 been shown to inhibit LH via dynorphin in the rat $(19,26)$, in a similar mechanism to that described

238 for $\mathrm{NKB}$ in the absence of $\mathrm{E}_{2}(38)$. Here, we further demonstrate that this inhibitory action of NKA

239 is mediated by the activation of the NKB-dynorphin pathway because the blockade of both NK3R

240 and KOR receptors ablates the inhibitory action of NKA. However, we unexpectedly observed

241 that in the absence of NKB, NKA no longer inhibits LH in the absence of $E_{2}$ but rather significantly

242 stimulates it (our present data in Tac2KO mice) in a process that is also SP-independent. This

243 suggests that when NKB is present, its inhibitory action (after being induced by NKA) is 
244 downstream of any stimulation induced by NKA which, as documented by our ISH data, would

245 act upstream of Kiss1 neurons. However, in the absence of NKB (and in the presence of a

246 functional NK3R, i.e. in Tac2KO mice), NKA is able to further stimulate LH release through a

247 mechanism that requires the activation of NK3R (because it is absent when this receptor is

248 blocked). This demonstrates that NKA's action on LH release is inherently stimulatory and

249 requires a functional NK3R, but not NKB.

250

251 Overall, in this study we have demonstrated that tachykinins are essential for the proper timing of

252 puberty onset in males and females and fertility maintenance in females. The absence of a single

253 tachykinin system may induce reproductive defects that can range from subtle to severe but can

254 eventually be reversed, and lead to successful reproduction, as observed in humans and mice

255 lacking NKB signaling. However, under the total absence of tachykinins, reproductive function is

256 severely compromised in the female supporting a compensatory role of the other tachykinin

257 systems, i.e. SP/NKA, in maintaining fertility. Despite this significant compensatory effect in the

258 tachykinin systems, it is remarkable that $20 \%$ of female Tac1/Tac2KO mice were able to deliver

259 pups. This suggests that higher hierarchical regulatory systems of Kiss1 neurons, e.g.

260 tachykinins, are not indispensable and additional mechanisms may develop to achieve

261 reproductive success although at very low levels. Male mice however, retain reproductive

262 capabilities after complete tachykinin removal, suggesting the existence of additional

263 mechanisms that ensure sufficient LH pulsatile release and/or the need of proper tachykinin

264 signaling in females to induce ovulation. This study offers new insights into the interaction and

265 mechanism of action of tachykinins in the control of LH release, especially related to NKA-NKB

266 interaction, which remained largely unexplored, and challenges the existing notion of NKB (and

267 tachykinins in general) as critical regulators of the $\mathrm{GnRH}$ pulse generator, at least in males. This

268 redundant tachykinin systems and the ability of NKA to compensate for NKB's action uncovers a

269 novel mechanism with potential clinical application to activate the gonadotropic axis in TAC3- 
270 deficient (but not TAC3R-deficient) patients, through the exogenous administration of NKA or

271 NK2R agonists to achieve reproductive success as occurs in sporadic $\mathrm{HH}$ reversal patients.

272

\section{Materials and Methods}

274 Mice. Wild-type (WT) female C57BI/6 mice were purchased from Charles River Laboratories

275 International, Inc. Tac2 KO (knockout, KO) mice were obtained from Dr. Seminara (MGH) (8).

276 Tac1/Tac2 KO were generated by crossing Tac1KO (The Jackson Laboratories, stock No.

277 004103) and Tac2KO mice. All animal studies were approved by the Harvard Medical Area

278 Standing Committee on the Use of Animals in Research and Teaching in the Harvard Medical

279 School Center for Animal Resources and Comparative Medicine. Mice were maintained in a 12:12

$280 \mathrm{~h}$ light/dark cycle and were fed standard rodent chow diet and water ad libitum. Genotyping was

281 conducted by PCR analyses on isolated genomic DNA from tail biopsies.

Reagents: The agonists of NK1R (GR73632), NK2R (GR64349) and NK3R (senktide), and the antagonists of NK3R (SB 222200) and NK1R (RP67580) were purchased from Tocris. Naloxone Hydrochloride (opioid receptor antagonist) and $\mathrm{GnRH}$, were purchased from Sigma Aldrich. Mouse kisspeptin-10 (Kp-10) was purchased from Phoenix pharmaceutical. All drugs were dissolved in saline $(0.9 \% \mathrm{NaCl})$, except for SB 222200 and RP67580, which were dissolved in $5 \%$ DMSO. Saline $(0.9 \% \mathrm{NaCl})$ was used as vehicle in all of our experiments. Doses and timings for hormonal analyses were selected on the basis of previous studies $(10,21,39)$.

\section{Experimental design}

292 General procedures: For intracerebroventricular (icv) injection, 2-3 days before the experiment, 293 the mice were briefly anesthetized with isoflurance and a small hole was bored in the skull $1 \mathrm{~mm}$ 294 lateral and $0.5 \mathrm{~mm}$ posterior to bregma with a Hamilton syringe attached to a 27-gauge needle 295 fitted with polyethylene tubing, leaving $3.5 \mathrm{~mm}$ of the needle tip exposed. Once the initial hole 


\section{7}

298

299

300

301

302

303

304

305

306

307

308

309

310

311

312

313

314

315

anesthetized with isoflurane for a total of 2-3 min, during which time $5 \mu$ l of solution were slowly and continuously injected into the lateral ventricle. The needle remained inserted for approximately $60 \mathrm{sec}$ after the injection to minimize backflow up the needle track. Mice typically recovered from the anesthesia within 3 min after the injection. For hormonal analyses, blood samples $(4 \mu \mathrm{l})$ were obtained from the tail and stored at $-80^{\circ} \mathrm{C}$ until hormonal determination. The dose and time of collection were selected based on our previous studies (10).

\section{Study 1: Reproductive maturation and function of Tac1/Tac2 KO female mice.}

Reproductive phenotyping (presence of vaginal opening (VO), timing of first estrus, ovarian weights) and fertility parameters (percentage of pregnancies, litter size and time to the first litter) were measured in female mice.

Littermate WT $(\mathrm{n}=12), \operatorname{Tac} 1 \mathrm{KO}(\mathrm{n}=12), \operatorname{Tac} 2 \mathrm{KO}(\mathrm{n}=5)$ and Tac1/Tac2 $\mathrm{KO}(\mathrm{n}=8)$ females were monitored daily from p25 (postnatal day) for: body weight (BW) and progression to VO (as indicated by complete canalization of the vagina). In addition, WT and Tac1/Tac2 KO females were monitored for the timing of first estrus during 90 days after the day of VO (first day with cornified cells determined by daily [in the morning] vaginal cytology). In addition, estrous cyclicity was monitored by daily vaginal cytology, for a period of 30 in WT and Tac1/Tac2 KO ( $\geq 8$ ). Cytology samples were obtained every morning (10 am) and placed on a glass slide for determination of the estrous cycle under the microscope as previously described (40).

The fertility assessment was performed by breeding adult WT $(n=3)$ or Tac1/Tac2 KO $(n=10)$ females with WT male previously proven to father litters. The time to the first litter and number of pups per litter were monitored.

The ovarian ultra-structure was analyzed in adult (3-4 month old) mice of the two genotypes: WT and Tac1/Tac2 KO (n=4). Ovaries were collected, weighed and fixed in Bouin's solution. The tissues were embedded in paraffin and sectioned $(10 \mu \mathrm{m})$ for hematoxylin and eosin staining (Harvard Medical School Rodent Pathology Core) and images acquired under $\times 4$ magnification. The ovaries were analyzed for presence of corpora lutea (CLs) per section. Each value represents the number of CLs of 1 representative section from the middle line of one ovary per animal. 
324 Study 2: Reproductive maturation and function of the Tac1/Tac2 KO male mouse.

325 Prepubertal littermate WT $(\mathrm{n}=11)$, Tac1 KO $(\mathrm{n}=6)$, Tac2 KO $(\mathrm{n}=6)$ and Tac1/Tac2 KO $(\mathrm{n}=14)$

326 males were monitored daily from p25 for preputial separation as an indirect marker of puberty

327 onset, and body weight was measured at the average age of puberty onset (PND28).

328 Adult WT $(n=3)$ or Tac1/Tac2 KO $(n=7)$ littermate mice (>PND75) were placed with proven fertile

329 WT females. Time to delivery and numbers of pups were monitored.

330 The testes' ultra-structure was analyzed in adult (3-4 month old) mice of the two genotypes: WT

331 and Tac1/Tac2 KO ( $\mathrm{n}=4)$. Testes were collected and processed as described above for ovaries.

332 Study 3: Characterization of the postgonadectomy response of $L H$ in females.

333 LH levels were measured in intact (diestrus in the morning) WT $(n=9)$, Tac2 KO $(n=4)$ and

334 Tac1/Tac2 KO ( $\mathrm{n}=6)$ adult (3-4 month) females and compared with $2 \mathrm{~d}$ and $7 \mathrm{~d}$ (days) after bilateral

335 ovariectomy (OVX). In addition, we assessed the pulsatile secretion of LH in adult OVX females

336 (4-week after OVX) Tac1/Tac2 KO mice and WT littermates ( $\mathrm{n}=6-7$ per group). Mice were handled

337 daily to allow acclimation to sampling conditions for three weeks prior to the experiment. Pulsatile

338 measurements of $\mathrm{LH}$ secretion were assessed by repeated blood collection through a single

339 excision at the tip of the tail, as described previously (41). The tail was cleaned with saline and

340 then massaged to take a 4 ul blood sample with a pipette. Whole blood was immediately diluted

341 in 116 ul of $0.05 \%$ PBST, vortexed, and frozen on dry ice. Samples were stored at $-80^{\circ} \mathrm{C}$ for a

342 subsequent LH ELISA. We collected 16 sequential blood samples over a 90 minutes sampling

343 period.

344 Study 4: Effect of $\mathrm{Kp}-10$ and $\mathrm{GnRH}$ administration on LH release in adult female mice.

345 Hormonal ( $\mathrm{LH}$ ) responses to known stimulators of $\mathrm{GnRH}$ and/or gonadotropin secretion were 346 studied in WT $(\mathrm{n}=7)$, Tac1 KO $(\mathrm{n}=8)$, Tac2 $\mathrm{KO}(\mathrm{n}=5)$ and Tac1/Tac2 $\mathrm{KO}(\mathrm{n}=7)$ mice. The mice

347 were injected with $\mathrm{GnRH}(0.25 \mathrm{ug} / 100 \mu \mathrm{l} / \mathrm{ip})$ and kisspeptin-10 (Kp-10) $(50 \mathrm{pmol} / \mathrm{mouse}$ in $5 \mu \mathrm{l} / \mathrm{icv})$,

348 and blood samples were obtained at 15-min after icv administration of Kp-10 and 30 min after ip

349 administration of $\mathrm{GnRH}$. Doses and routes of administration were selected in the basis of previous

350 references $(42,43)$. 
351 Study 5: Expression of Tacr1,Tacr2, Tacr3, Kiss1 and Pdyn in the mediobasal hypothalamus

$352(\mathrm{MBH})$ of female mice.

353 We aimed to determine if there are changes in the expression of Tacr1, Tacr2, Tacr3, Kiss1, and

354 Pdyn in the mediobasal hypothalamus $(\mathrm{MBH})$, the site that includes the arcuate nucleus (ARC)

355 between WT and Tac1/Tac2 KO intact females.

356 Total RNA from the $\mathrm{MBH}$ was isolated using TRIzol reagent (Invitrogen) followed by

357 chloroform/isopropanol extraction. RNA was quantified using NanoDrop 2000 spectrophotometer

358 (Thermo Scientific), and $1 \mu \mathrm{m}$ of RNA was reverse transcribed using iScript cDNA synthesis kit

359 (Bio-Rad). Quantitative real-time PCR assays were performed on an ABI Prism 7000 sequence

360 detection system, and analyzed using ABI Prism 7000 SDS software (Applied Biosystems). The

361 cycling conditions were the following: 2 min incubation at $95^{\circ} \mathrm{C}$ (hot start), 45 amplification cycles

$362\left(95^{\circ} \mathrm{C}\right.$ for $30 \mathrm{~s}, 60^{\circ} \mathrm{C}$ for $30 \mathrm{~s}$, and $45 \mathrm{~s}$ at $75^{\circ} \mathrm{C}$, with fluorescence detection at the end of each

363 cycle), followed by melting curve of the amplified products obtained by ramped increase of the

364 temperature from 55 to $95^{\circ} \mathrm{C}$ to confirm the presence of single amplification product per reaction.

365 For data analysis, relative standard curves were constructed from serial dilutions of one reference

366 sample cDNA and the input value of the target gene was standardized to Hprt levels in each

367 sample. The primers used are listed in Table 1.

368 Study 6: Characterization of the postgonadectomy response of LH in males.

369 Bilateral removal of testes from 3-4-month-old males was performed with light isoflurane 370 anesthesia. Briefly, the ventral skin was shaved and cleaned to perform one small incision in the 371 skin and abdominal musculature of the abdomen. Once the gonads were identified and excised,

372 the muscle incision was sutured and the skin was closed with surgical clips. LH levels were

373 measured in WT $(n=13)$, Tac2 $\mathrm{KO}(\mathrm{n}=4)$ and Tac1/Tac2 KO $(\mathrm{n}=10)$ mice. Blood samples were

374 collected before and $2 d$ and $7 d$ after bilateral gonadectomy (GNX).

375 Study 7: Effect of $\mathrm{Kp}-10$ and $\mathrm{GnRH}$ administration on $\mathrm{LH}$ release in adult male mice.

376 Hormonal ( $\mathrm{LH}$ ) responses to known stimulators of $\mathrm{GnRH}$ and/or gonadotropin secretion were 377 studied in WT (n=7-20), Tac1 KO (n=4-7), Tac2 KO (n=8-12) and Tac1/Tac2 KO (n=8-18) mice. 
378 The mice were injected with $\mathrm{GnRH}(0.25 \mathrm{ug} / 100 \mu \mathrm{l} / \mathrm{ip})$ and kisspeptin-10 (Kp-10) (50 pmol/mouse

379 in $5 \mu \mathrm{l} / \mathrm{icv}$ ), and blood samples were obtained at 15-min after icv administration of Kp-10 and 30

380 min after ip administration of $\mathrm{GnRH}$. Doses and routes of administration were selected in the basis

381 of previous references.

382 Study 8: Effect of chronic administration of NK2R-Ag in pre-pubertal mice.

383 To address if NKA/NK2R signaling plays a role in puberty onset, in the next experiment, we 384 performed a systemic chronic (p23 - 32) administration of NK2R-Ag (3 nmol/100 $\mu \mathrm{l} / \mathrm{ip})$ or vehicle

$385(0.9 \% \mathrm{NaCl})$ to female mice ( $\mathrm{n} \geq 6$ per group). Reproductive maturation (progression of VO) was 386 monitored daily. BW was registered at day 30 when $50 \%$ of control females showed VO. Also, 387 uterus and ovarian weight, as well as serum LH were determined at day 32, last day of NK2R-Ag 388 administration.

Study 9: Interaction between NKA, NKB and SP in the stimulation of $L H$ release in the presence of estradiol.

391 In this study, adult female mice were subjected to bilateral OVX via abdominal incision under light 392 isofluorane anesthesia 1 week before hormonal tests. Immediately after OVX, capsules filled with $393 E_{2}$ or vehicle (sesame seed oil) were implanted subcutaneously (sc) via a small midscapular 394 incision at the base of the neck; wound clips were used to close the incision. Silastic tubing (15 $395 \mathrm{~mm}$ long, 0.078 in inner diameter, 0.125 in outer diameter; Dow Corning) was used for capsule 396 preparation. Dilutions of crystalline $E_{2}$ at a low dose $(50 \mu \mathrm{g} / \mathrm{mL}$, in sesame oil) were used to fill 397 capsules. After capsules were filled, the end of the capsule was sealed with silicone cement and 398 allowed to cure overnight. On the day before surgery, implants were washed twice for 10 min in 399 changes of $100 \%$ ethanol and then placed in sterile physiological saline overnight.

400 First, we analyzed the possible additive effect of NK2R-Ag and senktide in LH secretion in the 401 presence of sex steroids. The LH level was measured at 25 and 60 min after icv injection of NK2R$402 \mathrm{Ag}$, senktide or the co-administration of both drugs. Then, OVX+E females ( $\mathrm{E} \geq 5$ per group) were 403 pretreated with SB222200 (7 nmol), 60 minutes prior to the icv injection of NK2R-Ag (600 pmol, 404 Senktinde or vehicle $(0.9 \% \mathrm{NaCl})$. Blood samples were collected before SB222200 injection 
405 (Basal) and at 25 and 60 minutes after injection. Additionally, we further analyzed the action of

406 NK2R-Ag in the absence of NKB signaling using Tac2 KO OVX+ $E_{2}$ females ( $\geq 5$ per group) that

407 were injected with NK2R-Ag (600 pmol) and blood samples were collected before and 25 and 60

408 min after injection. Finally, in order to evaluate the whether the action of NKA requires kisspeptin

409 to stimulate $\mathrm{LH}$ release, we used Kiss1 KO OVX+E females ( $\mathrm{N} \geq 5$ per group) and LH levels were

410 measured 25 min after icv injection of NK2R-Ag (600 pmol).

411 Study 10: Interaction between NKA, NKB and SP in the inhibition of $L H$ release in ovariectomized

412 (OVX) female mice.

413 Adult females were subjected to bilateral OVX via abdominal incision under light isofluorane

414 anesthesia 1 week before hormonal tests. First, we analyzed the possible additive effect of NK2R-

$415 \mathrm{Ag}$ and senktide in the inhibition of $\mathrm{LH}$ secretion in the absence of sex steroids. LH level was

416 measured at 25 and 60 min after icv injection of NK2R-Ag, senktide or the co-administration of

417 both drugs. In the next experiment we intended to assess the role of NKB in the inhibition of LH

418 secretion achieved by NKA in OVX females. To this end, LH responses to NK2R-Ag were

419 evaluated after blockade of the effects of NKB using SB222200 (7 nmol) as a selective antagonist

420 of NK3R. For this purpose, adult OVX female mice were pretreated with SB222200, 60 minutes

421 prior to the icv injection of NK2R-Ag (600 pmol). Blood samples were collected before SB222200

422 injection (Basal) and at 25 and 60 minutes after vehicle or NK2R-Ag injection. In addition, we

423 analyzed the role of endogenous opioids in the control of adult OVX females LH secretion and in

424 the modulation of responses to NK2R-Ag. To this end, LH responses to NK2R-Ag were measured

425 after the blockade of the opioid receptors $\kappa$ and $\mu$ (KOR and MOR) using naloxone

426 (5mg/kg/100ul/ip). The animals were injected with naloxone, 12 hours and 60 minutes prior to the

427 icv injection of NK2R-Ag (600 pmol). Blood samples were collected before naloxone injection and

428 at 25 and 60 minutes after NK2R-Ag injection. We further analyzed the action of NK2R-Ag in the

429 absence of NKB signaling and sex steroids using Tac2 KO OVX females ( $\mathrm{n} \geq 5$ per group), which

430 were injected with NK2R-Ag $(600 \mathrm{pmol})$ and blood samples were collected before and 25 and 60

431 min after injection. In addition, we evaluated the role of SP in the action of NK2R-Ag action in the 
432 inhibition of LH in WT OVX and Tac2KO OVX mice. WT OVX and Tac2KO OVX females $(n \geq 5$ per

433 group) were injected with NK1R-Antg (2 nmol), 30 min previously to the NK2R-Ag (600 pmol),

434 NK1R-Ag (600 pmol) or vehicle administration. Blood samples were collected before and 25 and

$43560 \mathrm{~min}$ after injection. Finally, we assess the ability of NK2R signaling to modulate LH release in

436 the absence of sex steroids and kisspeptin using Kiss1 KO OVX females ( $\geq 5$ per group) were

437 injected with NK2R-Ag (600 pmol) and LH levels were measured at 25 and 60 min after icv

438 injection.

440 In situ hybridization (ISH): To determine the presence of co-expression between Tac2r and

441 Tac1 mRNA in key areas (ventromedial nucleus, VMN; and ARC) dual fluorescence ISH was

442 performed in additional tissue samples from $\mathrm{OVX}+$ sham and $\mathrm{OVX}+\mathrm{E}_{2}$ animals. We used probes

443 for Tac2r-C1 and Tac1-C2 obtained from ACDBio and used the RNAscope method per their

444 protocol (ACDBio). The brains were removed for ISH, fresh frozen on dry ice, and then stored at

$445-80^{\circ} \mathrm{C}$ until sectioned. Five sets of $20-\mu \mathrm{m}$ sections in the coronal plane were cut on a cryostat,

446 from the diagonal band of Broca to the mammillary bodies, thaw mounted onto SuperFrost Plus

447 slides (VWR Scientific), and stored at $-80^{\circ} \mathrm{C}$. A single set was used for ISH experiment (adjacent

448 sections $100 \mu \mathrm{m}$ apart).

450 Hormone measurements: LH was measured by a sensitive sandwich ELISA for the assessment 451 of whole blood LH concentrations. A 96-wellhigh-affinity binding microplate (9018; Corning) was

452 coated with 50uL of capture antibody (monoclonal antibody, anti-bovine LH beta subunit, 518B7;

453 University of California) at a final dilution of 1:1000 (in 1XPBS, $1.09 \mathrm{~g}$ of Na2HPO4 [an-hydrous],

$4540.32 \mathrm{~g}$ of $\mathrm{NaH} 2 \mathrm{PO} 4$ [anhydrous], and $9 \mathrm{~g}$ of $\mathrm{NaCl}$ in1000 $\mathrm{mL}$ of distilled water) and incubated

455 overnight at $4^{\circ} \mathrm{C}$. To minimize unspecific binding of the capture antibody, wells were incubated

456 with $200 u \mathrm{~L}$ of blocking buffer $(5 \%$ [w/v] skim milk powder in 1 XPBS-T (1XPBS with $0.05 \%$

457 Tween20) for 2 hours at room temperature (RT).A standard curve was generated using a 2-fold

458 serial dilution of LH (reference preparation, AFP-5306A; National Institute of Diabetes and 
Digestive and Kidney Diseases National Hormone and Pituitary Program [NIDDK-NHPP]) in 0.2\% (w/v) BSA-1XPBS-T. The LH standards and blood samples were incubated with 50 uL of detection antibody (polyclonal antibody, rabbit LH antiserum, AFP240580Rb; NIDDK-NHPP) at a final dilution of 1:10000 for 1.5 hours (at RT). Each well containing bound substrate was incubated with $50 \mathrm{ul}$ of horseradish peroxidase conjugated antibody (poly-clonalgoatanti-rabbit, D0487012; DakoCytomation) at a final dilution of 1:2000. After a 1.5-hour incubation, 100Ul of o465 phenylenediamine (002003; Invitrogen), substrate containing $0.1 \% \mathrm{H} 2 \mathrm{O} 2$ was added to each well 466 and left at RT for 30 minutes. The reaction was stopped by addition of $50 \mathrm{uL}$ of $3 \mathrm{M} \mathrm{HCl}$ to each 467 well, and absorbance of each well was read at a wave length of $490 \mathrm{~nm}$ (Sunrise; Tecan Group). 468 The concentration of LH in whole blood samples was determined by interpolating the OD values of unknowns against a nonlinear regression of the LH standard curve (41).

471 Statistical Analysis: All data are expressed as the mean \pm SEM for each group. A two tailed

472 unpaired t-Student test or a one- or two-way ANOVA test followed by Tukey or Newman Kleus 473 post-hoc test was used to assess variation among experimental groups. Significance level was 474 set at $\mathrm{P}<0.05$. All analyses were performed with GraphPad Prism Software, Inc (San Diego, CA).

Statistical Analysis of LH pulses: Mice LH concentration time series were analyzed using a MATLAB-bases algorithm. It is a for loop written in the code to determine which LH peaks are

478 considered pulses. This for loop states that any peak whose height is $20 \%$ greater than the heights

479 of the 2 previous peaks as well as $10 \%$ greater than the height of the following peak is considered 480 a pulse. There is also a condition written into the code that is specific for the second time interval 481 ( $i=2)$ that states that the peak at the second-time interval only needs to be $20 \%$ greater than the 482 single peak that comes before it to be considered a pulse.

485 All animal care and experimental procedures were approved by the National Institute of Health, 486 and Brigham and Women's Hospital Institutional Animal Care and Use Committee, protocol 
\#05165. The Brigham and Women's Hospital is a registered research facility with the U.S.

Department of Agriculture (\#14-19), is accredited by the American Association for the

Accreditation of Laboratory Animal Care, and meets the National Institutes of Health standards

as set forth in the Guide for the Care and Use of Laboratory Animals (DHHS Publication No. (NIH)

85-23 Revised 1985).

492

\section{Author contributions}

SL and VMN conceived and designed the research. SL, CF, RT, SS, CAM and AG conducted experiments. SBS provided critical mouse lines. SL and VMN contributed to data analysis. SL and VMN wrote the manuscript, and all authors contributed to manuscript editing.

\section{Acknowledgments}

This work was supported by R01 HD090151 and Women's Brain Initiative of the Brigham and Women's Hospital to V.M.N. and The International Brain Research Organization (IRBO). Research Fellowship to RT. The authors declare no competing financial interests

\section{References}

1. Lasaga M, Debeljuk L. Tachykinins and the hypothalamo-pituitary-gonadal axis: An update. Peptides. 2011;32(9):1972-8.

2. Cao YQ, Mantyh PW, Carlson EJ, Gillespie AM, Epstein CJ, Basbaum Al. Primary afferent tachykinins are required to experience moderate to intense pain. Nature. 1998;392(6674):3904.

3. Fergani C, Navarro VM. Expanding the Role of Tachykinins in the Neuroendocrine Control of Reproduction. Reproduction (Cambridge, England). 2016;153(1):R1-R14.

4. Topaloglu AK, Reimann F, Guclu M, Yalin AS, Kotan LD, Porter KM, et al. TAC3 and TACR3 mutations in familial hypogonadotropic hypogonadism reveal a key role for Neurokinin $B$ in the central control of reproduction. Nat Genet. 2009;41(3):354-8.

5. Young J, Bouligand J, Francou B, Raffin-Sanson ML, Gaillez S, Jeanpierre M, et al. TAC3 and TACR3 defects cause hypothalamic congenital hypogonadotropic hypogonadism in humans. J Clin Endocrinol Metab. 2010;95(5):2287-95.

6. Gianetti E, Tusset C, Noel SD, Au MG, Dwyer AA, Hughes VA, et al. TAC3/TACR3 mutations reveal preferential activation of gonadotropin-releasing hormone release by neurokinin $B$ in neonatal life followed by reversal in adulthood. J Clin Endocrinol Metab. 2010;95(6):2857-67.

7. Yang JJ, Caligioni CS, Chan YM, Seminara SB. Uncovering novel reproductive defects in neurokinin $B$ receptor null mice: closing the gap between mice and men. Endocrinology. 2012;153(3):1498-508. 
525 8. True C, Nasrin Alam S, Cox K, Chan YM, Seminara S. Neurokinin B is critical for normal 526 timing of sexual maturation but dispensable for adult reproductive function in female mice. 527 Endocrinology. 2015:en20141862.

528 9. de Croft S, Boehm U, Herbison AE. Neurokinin B activates arcuate kisspeptin neurons 529 through multiple tachykinin receptors in the male mouse. Endocrinology. 2013;154(8):2750-60.

530 10. Navarro VM, Bosch MA, Leon S, Simavli S, True C, Pinilla L, et al. The integrated 531 hypothalamic tachykinin-kisspeptin system as a central coordinator for reproduction. 532 Endocrinology. 2015;156(2):627-37.

533 11. Arisawa M, De Palatis L, Ho R, Snyder GD, Yu WH, Pan G, et al. Stimulatory role of 534 substance $P$ on gonadotropin release in ovariectomized rats. Neuroendocrinology. 1990;51(5):523-9.

536 12. Coiro V, Volpi R, Capretti L, Caiazza A, Marcato A, Bocchi R, et al. Luteinizing hormone 537 response to an intravenous infusion of substance $P$ in normal men. Metabolism: clinical and 538 experimental. 1992;41(7):689-91.

539 13. Traczyk WZ, Pau KY, Kaynard AH, Spies HG. Modulatory role of substance P on gonadotropin and prolactin secretion in the rabbit. J Physiol Pharmacol. 1992;43(3):279-97.

14. Rance NE, Bruce TR. Neurokinin B gene expression is increased in the arcuate nucleus of ovariectomized rats. Neuroendocrinology. 1994;60(4):337-45.

543 15. Hrabovszky E, Borsay BA, Racz K, Herczeg L, Ciofi P, Bloom SR, et al. Substance p 544 immunoreactivity exhibits frequent colocalization with kisspeptin and neurokinin $B$ in the human infundibular region. PloS one. 2013;8(8):e72369.

546 16. Simavli S, Thompson IR, Maguire CA, Gill JC, Carroll RS, Wolfe A, et al. Substance $p$ 547 regulates puberty onset and fertility in the female mouse. Endocrinology. 2015;156(6):2313-22.

548 17. Maguire CA, Song YB, Wu M, Leon S, Carroll RS, Alreja M, et al. Tac1 Signaling is Required 549 for Sexual Maturation and Responsiveness of GnRH Neurons to Kisspeptin in the Male Mouse. 550 Endocrinology. 2017.

551 18. Ruiz-Pino F, Garcia-Galiano D, Manfredi-Lozano M, Leon S, Sanchez-Garrido MA, Roa J, et 552 al. Effects and interactions of tachykinins and dynorphin on FSH and LH secretion in developing 553 and adult rats. Endocrinology. 2015;156(2):576-88.

554 19. Sahu A, Kalra SP. Effects of tachykinins on luteinizing hormone release in female rats: 555 potent inhibitory action of neuropeptide K. Endocrinology. 1992;130(3):1571-7.

556 20. Steinhoff MS, von Mentzer B, Geppetti P, Pothoulakis C, Bunnett NW. Tachykinins and 557 their receptors: contributions to physiological control and the mechanisms of disease. 558 Physiological reviews. 2014;94(1):265-301.

559 21. Navarro VM, Ruiz-Pino F, Sanchez-Garrido MA, Garcia-Galiano D, Hobbs SJ, Manfredi560 Lozano $M$, et al. Role of neurokinin $B$ in the control of female puberty and its modulation by 561 metabolic status. The Journal of neuroscience : the official journal of the Society for 562 Neuroscience. 2012;32(7):2388-97.

563 22. George JT, Kakkar R, Marshall J, Scott ML, Finkelman RD, Ho TW, et al. Neurokinin B 564 Receptor Antagonism in Women With Polycystic Ovary Syndrome: A Randomized, Placebo565 Controlled Trial. J Clin Endocrinol Metab. 2016;101(11):4313-21.

566 23. Li SY, Li XF, Hu MH, Shao B, Poston L, Lightman SL, et al. Neurokinin B receptor antagonism 567 decreases luteinising hormone pulse frequency and amplitude and delays puberty onset in the 568 female rat. Journal of neuroendocrinology. 2014;26(8):521-7. 
24. Nakamura S, Wakabayashi Y, Yamamura T, Ohkura S, Matsuyama S. A neurokinin 3 receptor-selective agonist accelerates pulsatile luteinizing hormone secretion in lactating cattle. Biology of reproduction. 2017;97(1):81-90.

25. Noritake K, Matsuoka T, Ohsawa T, Shimomura K, Sanbuissho A, Uenoyama Y, et al. Involvement of neurokinin receptors in the control of pulsatile luteinizing hormone secretion in rats. The Journal of reproduction and development. 2011;57(3):409-15.

26. Kalra PS, Sahu A, Bonavera JJ, Kalra SP. Diverse effects of tachykinins on luteinizing hormone release in male rats: mechanism of action. Endocrinology. 1992;131(3):1195-201.

27. Navarro VM, Gottsch ML, Chavkin C, Okamura H, Clifton DK, Steiner RA. Regulation of gonadotropin-releasing hormone secretion by kisspeptin/dynorphin/neurokinin B neurons in the arcuate nucleus of the mouse. The Journal of neuroscience : the official journal of the Society for Neuroscience. 2009;29(38):11859-66.

28. Navarro VM. New insights into the control of pulsatile GnRH release: the role of Kiss1/neurokinin B neurons. Frontiers in endocrinology. 2012;3:48.

29. Gill JC, Navarro VM, Kwong C, Noel SD, Martin C, Xu S, et al. Increased neurokinin B (Tac2) expression in the mouse arcuate nucleus is an early marker of pubertal onset with differential sensitivity to sex steroid-negative feedback than Kiss1. Endocrinology. 2012;153(10):4883-93.

30. Clarkson J, Han SY, Piet R, McLennan T, Kane GM, Ng J, et al. Definition of the hypothalamic GnRH pulse generator in mice. Proceedings of the National Academy of Sciences of the United States of America. 2017;114(47):E10216-E23.

31. Deal MJ, Hagan RM, Ireland SJ, Jordan CC, McElroy AB, Porter B, et al. Conformationally constrained tachykinin analogues: potent and highly selective neurokinin NK-2 receptor agonists. Journal of medicinal chemistry. 1992;35(22):4195-204.

32. Seabrook GR, Bowery BJ, Hill RG. Pharmacology of tachykinin receptors on neurones in the ventral tegmental area of rat brain slices. Eur J Pharmacol. 1995;273(1-2):113-9.

33. Smith JT, Cunningham MJ, Rissman EF, Clifton DK, Steiner RA. Regulation of Kiss1 gene expression in the brain of the female mouse. Endocrinology. 2005;146(9):3686-92.

34. Hidalgo-Diaz C, Castano JP, Lopez-Pedrera R, Malagon MM, Garcia-Navarro S, GraciaNavarro F. A modulatory role for substance $P$ on the regulation of luteinizing hormone secretion by cultured porcine gonadotrophs. Biology of reproduction. 1998;58(3):678-85.

35. Hidalgo-Diaz C, Malagon MM, Garcia-Navarro S, Luque RM, Gonzalez de Aguilar JL, GraciaNavarro F, et al. Role of $\mathrm{Ca} 2+$ in the secretory and biosynthetic response of porcine gonadotropes to substance $P$ and gonadotropin-releasing hormone. Regul Pept. 2003;116(1-3):43-52.

36. Kerdelhue B, Tartar A, Lenoir V, el Abed A, Hublau P, Millar RP. Binding studies of substance $P$ anterior pituitary binding sites: changes in substance $P$ binding sites during the rat estrous cycle. Regul Pept. 1985;10(2-3):133-43.

37. Shamgochian MD, Leeman SE. Substance P stimulates luteinizing hormone secretion from anterior pituitary cells in culture. Endocrinology. 1992;131(2):871-5.

38. Kinsey-Jones JS, Grachev P, Li XF, Lin YS, Milligan SR, Lightman SL, et al. The inhibitory effects of neurokinin $B$ on $\mathrm{GnRH}$ pulse generator frequency in the female rat. Endocrinology. 2012;153(1):307-15.

39. Leon S, Barroso A, Vazquez MJ, Garcia-Galiano D, Manfredi-Lozano M, Ruiz-Pino F, et al. Direct Actions of Kisspeptins on GnRH Neurons Permit Attainment of Fertility but are Insufficient to Fully Preserve Gonadotropic Axis Activity. Sci Rep. 2016;6:19206.

40. Martin C, Navarro VM, Simavli S, Vong L, Carroll RS, Lowell BB, et al. Leptin-responsive GABAergic neurons regulate fertility through pathways that result in reduced kisspeptinergic 
615 tone. The Journal of neuroscience : the official journal of the Society for Neuroscience. 616 2014;34(17):6047-56.

617 41. Steyn FJ, Wan Y, Clarkson J, Veldhuis JD, Herbison AE, Chen C. Development of a 618 methodology for and assessment of pulsatile luteinizing hormone secretion in juvenile and adult 619 male mice. Endocrinology. 2013;154(12):4939-45.

620 42. Garcia-Galiano D, Pineda R, Roa J, Ruiz-Pino F, Sanchez-Garrido MA, Castellano JM, et al. 621 Differential modulation of gonadotropin responses to kisspeptin by aminoacidergic, peptidergic, 622 and nitric oxide neurotransmission. American journal of physiology Endocrinology and 623 metabolism. 2012;303(10):E1252-63.

624 43. Garcia-Galiano D, van Ingen Schenau D, Leon S, Krajnc-Franken MA, Manfredi-Lozano M, 625 Romero-Ruiz A, et al. Kisspeptin signaling is indispensable for neurokinin B, but not glutamate, 626 stimulation of gonadotropin secretion in mice. Endocrinology. 2012;153(1):316-28.

627

628

629

630

631

632 Figure legends

633

634

635

636

637

638

639

640

641

642

643

644

645

646

\section{Complete absence of tachykinins in double Tac1/Tac2 $\mathrm{KO}$ females severely disrupts} puberty onset and fertility in females.

(A) Accumulated percentage of mice with vaginal opening (VO), an indirect assessment of puberty onset by daily visualization for two weeks post weaning (WT n=12; Tac1 KO n=12;Tac2 $\mathrm{KO}$ n=5 and Tac1/Tac2 KO n=8). (B) Mean postnatal day of VO and (C) BW the day of VO (WT $\mathrm{n}=12 ; \operatorname{Tac} 1 \mathrm{KO}$ n=12; Tac2 KO n=5 and Tac1/Tac2 KO n=8). Different letters indicate statistically different values (2 Way ANOVA followed by Newman Kleus post-hoc test, $p<0.05$ ). (D) Mean postnatal day of first estrous as determined by histology samples taken over the course of 30 days after VO (WT n=9 and Tac1/Tac2 KO n=8). (E) Fertility test in which adult WT and Tac1/Tac2 KO females were mated with proven fertile WT males (WT $\mathrm{n}=3$ and Tac1/Tac2 KO $\mathrm{n}=10$ ). Percentage of females that delivered pups. (F) Number of pups per litter for one set of breeding pairs over 90 days of ongoing breeding is significantly lower in Tac1/Tac2 KO. ${ }^{* *} \mathrm{p}<0.01$ Student t-test. (G) Parturition latency in WT $(n=3)$ and Tac1/Tac2 KO $(n=10)$ mice. ${ }^{* *} p<0.01$ Student ttest. (H) Ovarian histology of WT $(n=3)$ and Tac1/Tac2 KO mice $(n=10)$. Each asterisk denotes 
647 a corpus luteum. (I) Number of corpora lutea in the middle section of the ovary from WT $(n=4)$

648 and Tac1/Tac2 KO (n=4) female mice. ${ }^{* * *} p<0.001$ Student t-test. (J) Representative examples of

649 daily estrous cycle phases over 30 days in 3-month-old WT ( $\mathrm{n}=7)$ and Tac1/Tac2 KO $(\mathrm{n}=8)$ female

650 mice. Days on estrous phase (E), proestrous phase (P) and diestrous phase (D). WT and

651 Tac1/Tac2 KO. * $p<0.05$ Student t-test; ${ }^{* *} p<0.01$ Student t-test. (K) Representative examples of

652 daily estrous cycle phases over 30 days in 8-month-old WT ( $n=4)$ and Tac1/Tac2 KO (n=6) female

653 mice. Days on estrous phase (E), proestrous phase $(P)$ and diestrous phase (D). WT and

654 Tac1/Tac2 KO. * $p<0.05$ Student t-test; ${ }^{* *} p<0.01$ Student t-test.

655

2. Tac1/Tac2 KO females display disrupted LH pulses and increased response to ovariectomy over 21 days.

(A) Representative pattern of LH pulsatility over 150 min (WT n=6 and Tac1/Tac2 KO n=7).

Analyzed using a MATLAB-bases algorithm. (B) Number of pulses over a 90 minutes sampling period. ${ }^{* *} p<0.01$ Student t-test. (C) Area under the curve (AUC) of the pattern of LH pulsatility over 150 min. Student t-test. (D) Circulating LH levels before and 2d, 7d, 14d and 21d (days) after bilateral ovariectomy (OVX). WT (n=9), Tac2 KO $(n=4)$ and Tac1/Tac2 KO $(n=6){ }^{*} p<0.05$; ${ }^{* *} p<0.01$ vs. corresponding basal (pre-OVX) levels; 2 Way ANOVA followed by Tukey post hoc test; \#p<0.05; \#\#< <0.01, KO vs. corresponding WT at each specific time point. (E) Circulating LH levels $15 \mathrm{~min}$ after the injection of kisspeptin-10 (50 pmol/5ul/icv). WT ( $n=7)$, Tac1 KO (n=8), Tac2 KO (n=5) and Tac1/Tac2 KO (n=7). Different letters indicate statistically different values (2 Way ANOVA followed by Tukey post-hoc test, $p<0.05)$. (F) Circulating LH levels 30 min after the injection of $\mathrm{GnRH}(0.25 \mathrm{ug} / 100 \mu \mathrm{l} / \mathrm{ip})$. WT $(\mathrm{n}=7)$, Tac1 KO $(\mathrm{n}=8)$, Tac2 $\mathrm{KO}(\mathrm{n}=5)$ and Tac1/Tac2 KO (n=7). Different letters indicate statistically different values (2 Way ANOVA followed by Tukey

670 post hoc test, $\mathrm{p}<0.05)$. (G, H) Expression of Tac1r, Tacr2, Tacr3, Kiss1 and Pdyn in the 671 mediobasal hypothalamus of $\operatorname{Tac} 2 \mathrm{KO}(\mathbf{G})$ and Tac1/Tac2KO (H) females and their WT controls. 672 WT $(\mathrm{n}=7)$, Tac2 KO $(\mathrm{n}=9)$ and Tac1/Tac2 KO $(\mathrm{n}=7)$. 


\section{3. Complete absence of tachykinins in double Tac1/Tac2 KO males delays puberty onset}

675 without affecting fertility.

676 (A) Accumulated percentage of mice with preputial separation (PS) as an indirect marker of

677 puberty onset for two weeks post weaning, WT ( $n=11)$, Tac1 KO $(n=6)$, Tac2 KO ( $n=6)$ and

678 Tac1/Tac2 KO (n=14). (B) Mean postnatal day of PS and (C) BW the day of PS (WT n=12; Tac1

$679 \mathrm{KO}$ n=12; Tac2 KO n=5 and Tac1/Tac2 KO n=8). (D) Percentage of success to impregnate WT

680 females (WT n=3 and Tac1/Tac2 KO n=7). (E) Number of pups per litter over 90 days of breeding

681 and (F) parturition latency. (G) Testicular histology was normal in Tac1/Tac2 KO compared to

682 controls, showing mature sperm in all cases (WT n=4 and Tac1/Tac2 KO n=4). (H) Circulating LH

683 levels before and 2d, 7d, 14d and 21d (days) after bilateral gonadectomy (GNX). WT (n=13), Tac2

$684 \mathrm{KO}(\mathrm{n}=4)$ and Tac1/Tac2 KO $(n=10) ;{ }^{* *} p<0.01$ vs. corresponding basal (pre-GNX) levels;

$685 \# p<0.05, \mathrm{KO}$ vs. corresponding WT at each specific time point. (I) Circulating LH levels 15 min 686 after the injection of kisspeptin-10 (50 pmol/5ul/icv). WT ( $\mathrm{n}=20)$, Tac1 KO (n=7), Tac2 KO ( $\mathrm{n=12})$

687 and Tac1/Tac2 KO ( $\mathrm{n=18}$ ). Different letters indicate statistically different values (2 Way ANOVA

688 followed by Tukey post hoc test, $\mathrm{p}<0.05)$. (J) Circulating LH levels 30 min after the injection of 689 GnRH $(0.25 \mathrm{ug} / 100 \mu \mathrm{l} / \mathrm{ip})$. WT $(\mathrm{n}=7)$, Tac1 KO $(\mathrm{n}=4)$, Tac2 KO $(\mathrm{n}=8)$ and Tac1/Tac2 KO $(\mathrm{n}=8)$.

690 Different letters indicate statistically different values (2 Way ANOVA followed by Tukey post hoc 691 test, $p<0.05)$

\section{The receptor of NKA (NK2R) is expressed in VMH Tac1 neurons.}

694 Representative double label ISH depicting co-localization of Tac1 (red) and Tacr2 (green) mRNA. 695 (A) VMH and (C) ARC of female WT C57BI/6 mice after 1 week of OVX. (B) VMH and (D) ARC 696 of female WT C57BI/6 OVX mice after 1 week of $E_{2}$ replacement.

\section{Advancement of puberty onset after chronic activation of NK2R in female mice.}

699 Repeated stimulation (every 12 h) of WT female mice with GR64349 (NK2R-A, 3 nmol/100ul/ip)

700 or vehicle $(0.9 \% \mathrm{NaCl} / 100 \mathrm{ul} / \mathrm{ip})$ from p23 to p32 ( $\mathrm{n} \geq 6$ per group). (A) Progression of VO, (B) mean 
701 postnatal day of VO and (C) BW the day of $50 \%$ of the control animals displayed VO. (D) Uterine

702 weight, (E) ovarian weight and (F) serum LH levels at p32. Statistical analysis was performed

703 using a 2-tailed t test $\left({ }^{*} p<0.05 ;{ }^{* * *} p<.001\right)$.

704

6. The stimulatory action of NKA is independent of NKB in the presence of physiological circulating levels of E2.

707 (A) LH release before (basal), 25 and 60 min after the icv injection of NK2R-Ag, senktide or the co-administration of both (600 pmol/5ul/icv) in WT OVX+E $\mathrm{E}_{2}$ females ( $\mathrm{n} \geq 5$ per group). * $\mathrm{p}<0.05$ vs. corresponding basal levels. (2 Way ANOVA followed by Tukey post hoc test). (B) LH levels before (basal) SB222200 (7 nmol5ul/icv) administration and at 25 and 60 minutes after injection of NK2R-Ag (600 pmol/5ul/icv), senktide (600 pmol/5ul/icv) or vehicle $(0.9 \% \mathrm{NaCl} / 5 \mathrm{ul} / \mathrm{icv})$ in WT

712 OVX $+E_{2}$ females ( $n \geq 4$ per group). ${ }^{*} p<0.05$ vs. corresponding basal levels. \# $p<0.05$ vs. corresponding control mice at the same time point (2 Way ANOVA followed by Tukey post hoc test). (C) LH before (Basal) and at 25 and 60 minutes after injection of NK2R-Ag (600 pmol/5ul/icv) in OVX+E $E_{2}$ WT and Tac2KO females ( $\mathrm{n} \geq 5$ per group). * $p<0.05$ vs. corresponding basal levels ( 2 Way ANOVA followed by Tukey post hoc test).

\section{The inhibitory action of NKA is NKB and dynorphin dependent.}

719 (A) LH release before (basal), 25 and 60 min after icv injection of NK2R-Ag, senktide or the co720 administration of both (600 pmol/5ul/icv) in WT OVX females ( $n \geq 5$ per group). * $p<0.05$ vs.

721 corresponding basal levels; \# p<0.05 vs. NK2R-Ag at the same time point (2 Way ANOVA 722 followed by Tukey post hoc test).

723 (B) LH levels before (basal) SB222200 (7 nmol5ul/icv) injection and at 25 and 60 minutes after 724 injection of NK2R-Ag (600 pmol/5ul/icv), senktide (600 pmol/5ul/icv) or vehicle $(0.9 \% \mathrm{NaCl} / 5 \mathrm{ul} / \mathrm{icv})$

725 in WT OVX females ( $n \geq 5$ per group). ${ }^{*} p<0.05$ vs. corresponding basal levels ( 2 Way ANOVA 726 followed by Tukey post hoc test). C) LH levels before (basal), 25 and 60 minutes after injection of 727 naloxone $(5 \mathrm{mg} / \mathrm{kg} / 100 \mathrm{ul} / \mathrm{ip})$ or vehicle $(0.9 \% \mathrm{NaCl} / 100 \mathrm{ul} / \mathrm{ip})$ in WT OVX females ( $\mathrm{n} \geq 5$ per group). 
$728{ }^{*} \mathrm{p}<0.05$ vs. corresponding basal levels (2 Way ANOVA followed by Tukey post hoc test). (D) LH

729 levels before (basal) and at 25 and 60 minutes after injection of NK2R-Ag (600 pmol/5ul/icv) in

730 OVX WT and OVX Tac2KO females ( $\mathrm{n} \geq 5$ per group). ${ }^{*} \mathrm{p}<0.05$ vs. corresponding basal levels (2

731 Way ANOVA followed by Tukey post hoc test). \# $p<0.05$; \# $p<0.01$ vs. corresponding WT levels

732 (2 Way ANOVA followed by Tukey post hoc test). E) LH levels before (basal) and at 25 and 60

733 minutes after injection of NK1R-Ag (600 pmol/5ul/icv), NK2R-Ag (600 pmol/5ul/icv) or vehicle

$734(0.9 \% \mathrm{NaCl} / 5 \mathrm{ul} / \mathrm{icv})$ in WT OVX females ( $\mathrm{n} \geq 5$ per group). Groups $2-4$ were pre-injected $30 \mathrm{~min}$

735 before the basal sample with NK1R-Antg $(2 \mathrm{nmol} / 5 \mathrm{ul} / \mathrm{icv}) . \quad{ }^{*} \mathrm{p}<0.05 \mathrm{vs}$. corresponding basal levels

736 (2 Way ANOVA followed by Tukey post hoc test); \# $p<0.05$ vs. NK1R-Antg + vehicle injected

737 mice levels. (F) LH release before (basal) NK1R-Antg (2 nmol/5ul/icv) injection and at 25 and 60

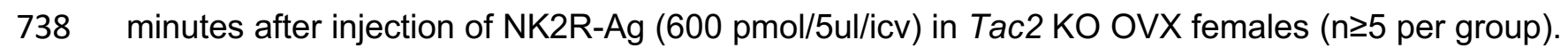

$739{ }^{*} \mathrm{p}<0.05$ vs. corresponding basal levels ( 2 Way ANOVA followed by Tukey post hoc test); \# $p<0.05$

740 vs. vehicle injected mice. 
Table 1: List of primers used for PCR determination.

\begin{tabular}{|c|c|c|}
\hline $\begin{array}{l}\text { Gene } \\
\text { Name }\end{array}$ & Primer Sequence & $\begin{array}{c}\text { Gene Accession } \\
\text { Number }\end{array}$ \\
\hline Hprt & $\begin{array}{l}\text { F: CCTGCTGGATTACATTAAAGCGCTG } \\
\text { R: GTCAAGGGCATATCCAACAACAAAC }\end{array}$ & NM_013556.2 \\
\hline Tacr1 & $\begin{array}{l}\text { F: GTCTGCCAAGAGCCAAGAAC } \\
\text { R: CCAGCCACATCTGAGAGACA }\end{array}$ & NM_009313 \\
\hline Tacr2 & $\begin{array}{l}\text { F: TCAACTTCATCTATGCCAGTCAC } \\
\text { R: ATGACAGCAATAACCGCCTTG }\end{array}$ & NM_009314 \\
\hline Tacr3 & $\begin{array}{l}\text { F: GCCATTGCAGTGGACAGGTAT } \\
\text { R: ACGGCCTGGCATGACTTTTA }\end{array}$ & NM_021382.6 \\
\hline Kiss1 & $\begin{array}{l}\text { F: CTCTGTGTCGCCACCTATGC } \\
\text { R: TTCCCAGGCATTAACGAGTTC }\end{array}$ & AF472576.1 \\
\hline Pdyn & $\begin{array}{l}\text { F: ACAGGGGGAGACTCTCATCT } \\
\text { R: GGGGATGAATGACCTGCTTACT }\end{array}$ & NM_018863.4 \\
\hline
\end{tabular}

Abbreviations: $F$, forward; $R$, reverse. 
A

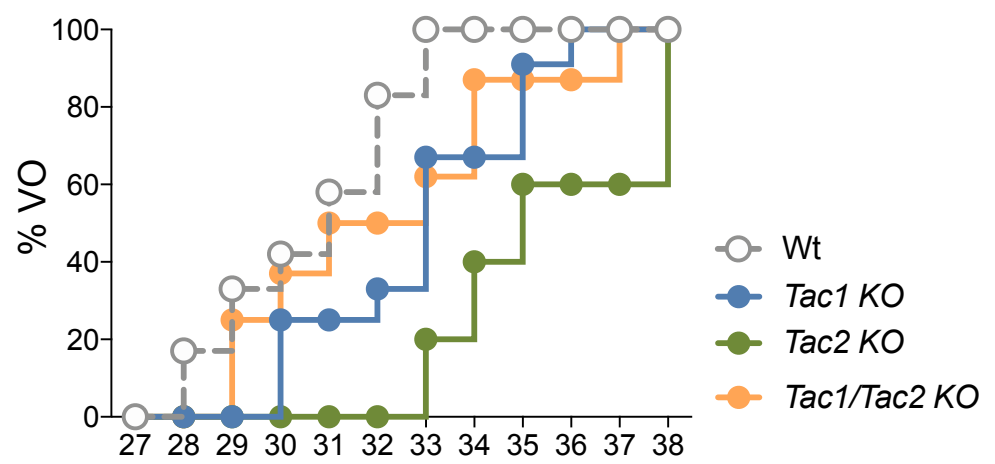

D

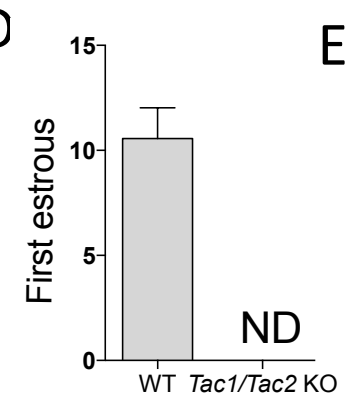

I
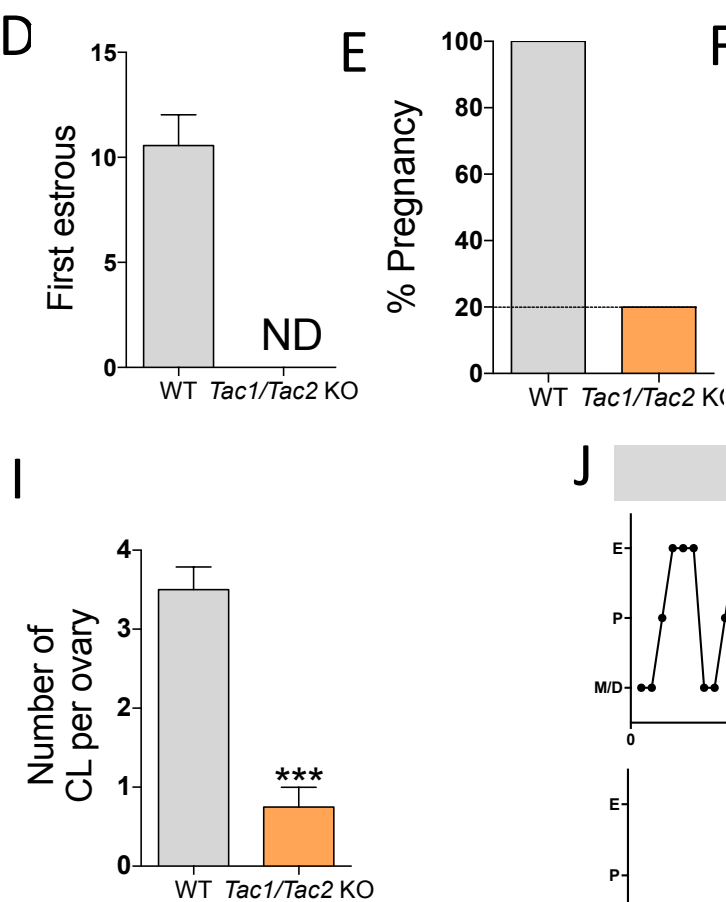

$\mathrm{J}$

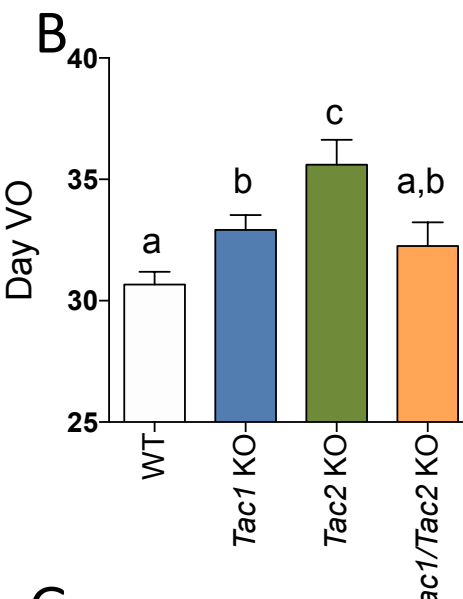

C

G
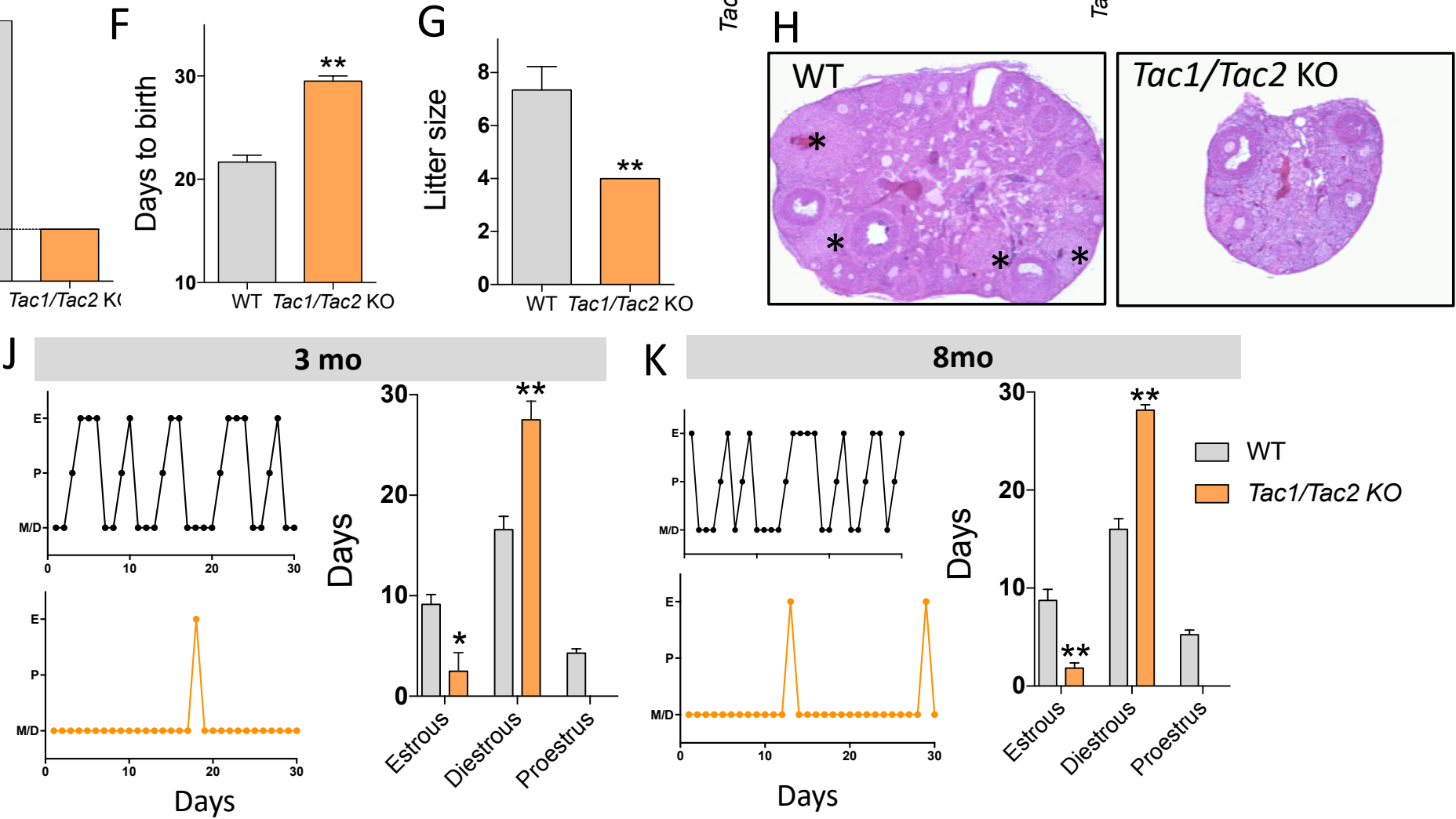

$3 \mathrm{mo}$
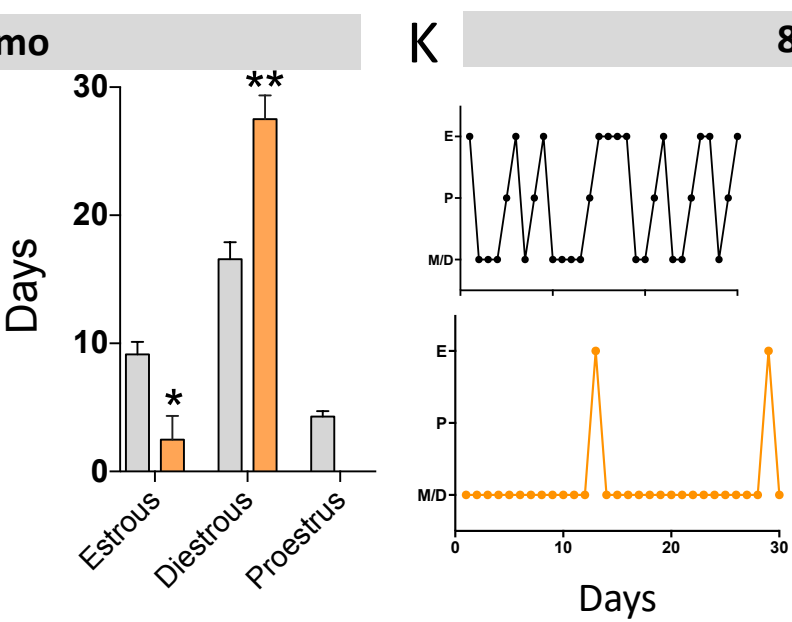

$8 \mathrm{mo}$

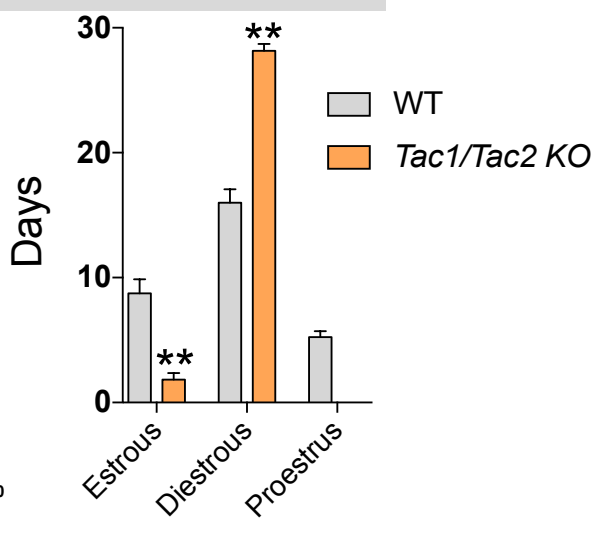

Figure 1 

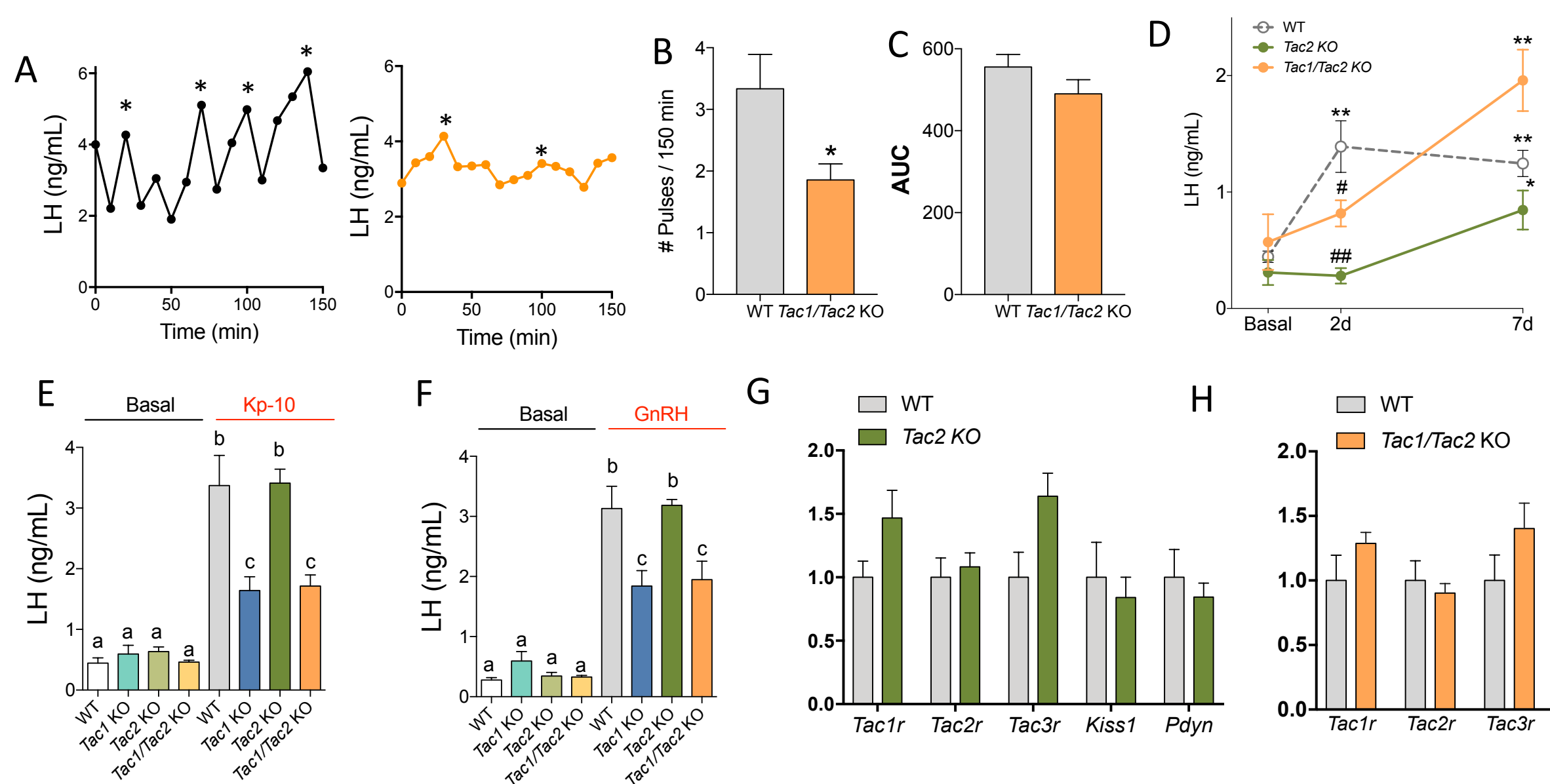

G
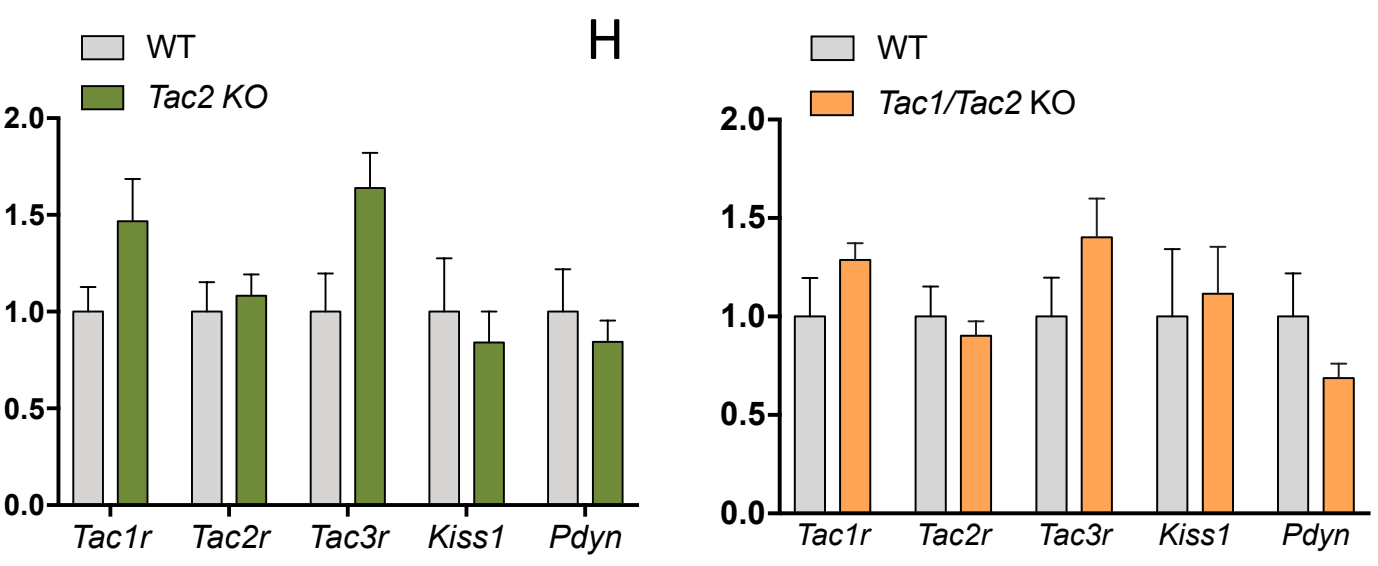

Figure 2 
A

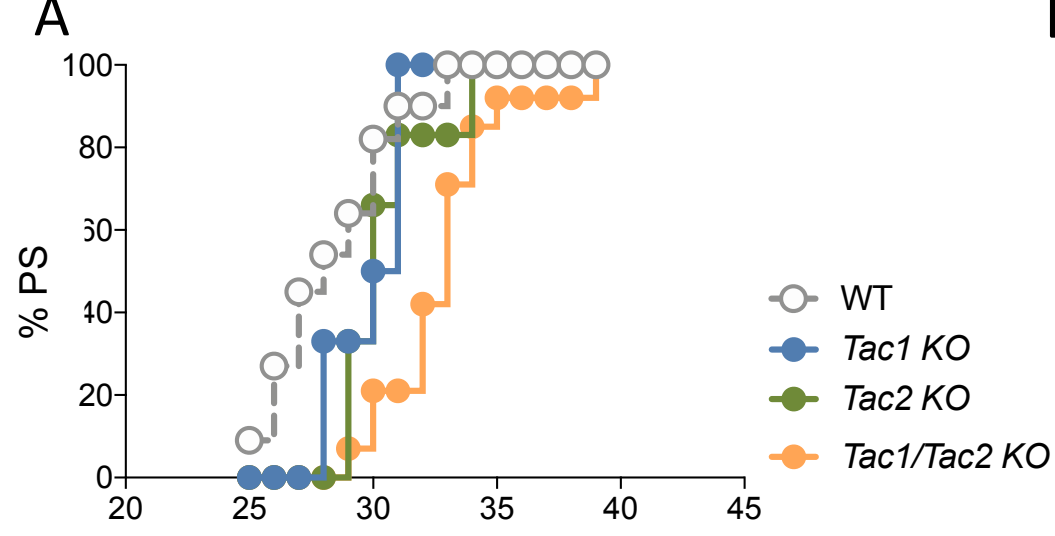

D

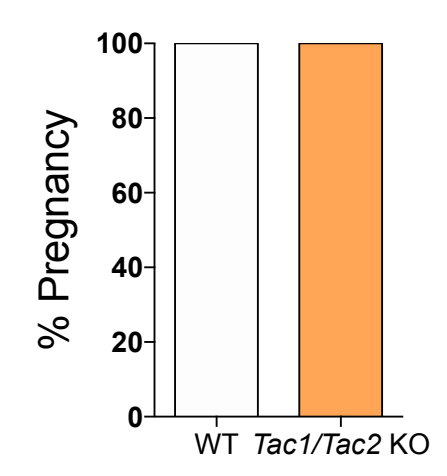

$\mathrm{H}$

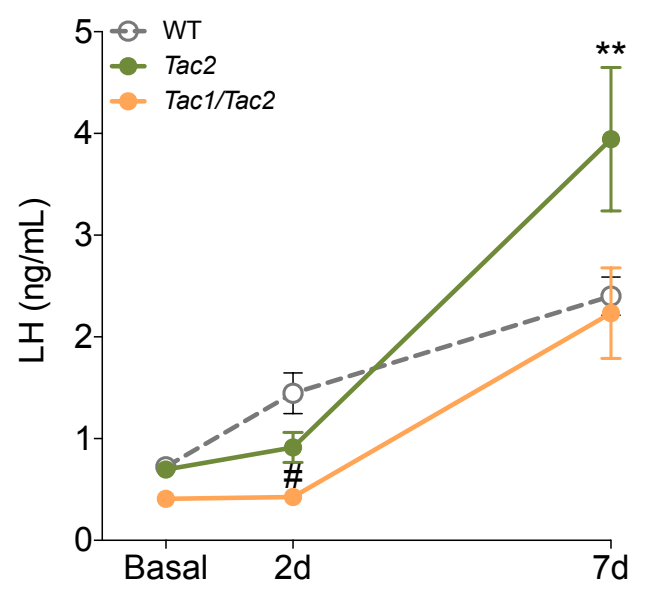

F

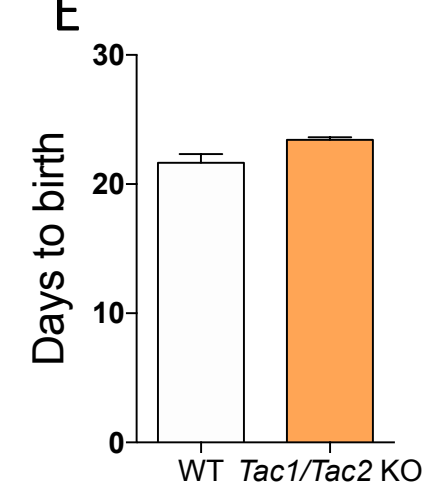

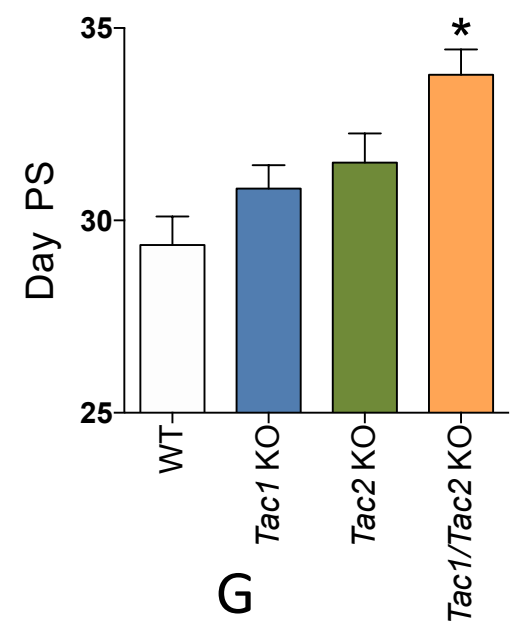
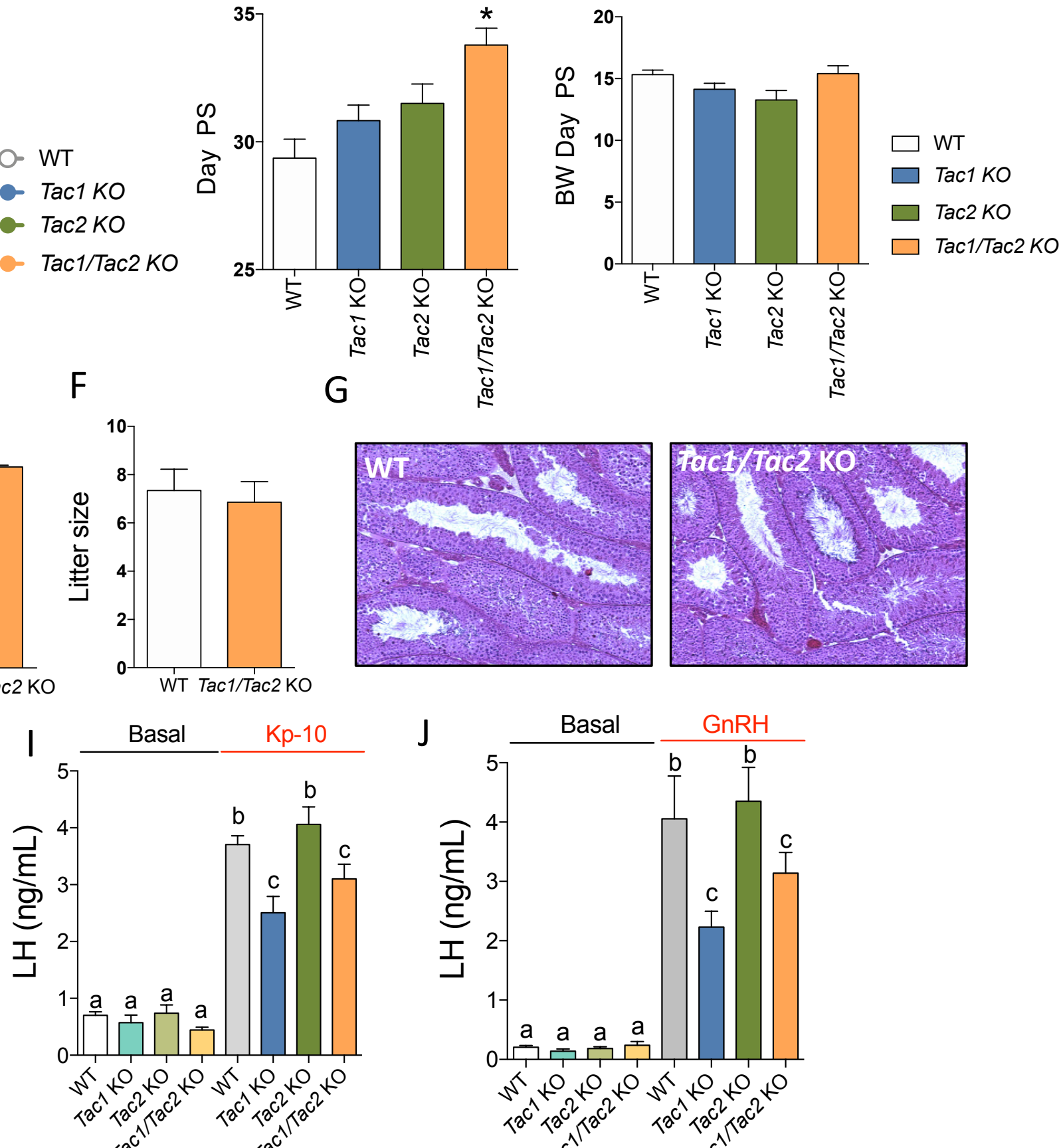

Figure 3 

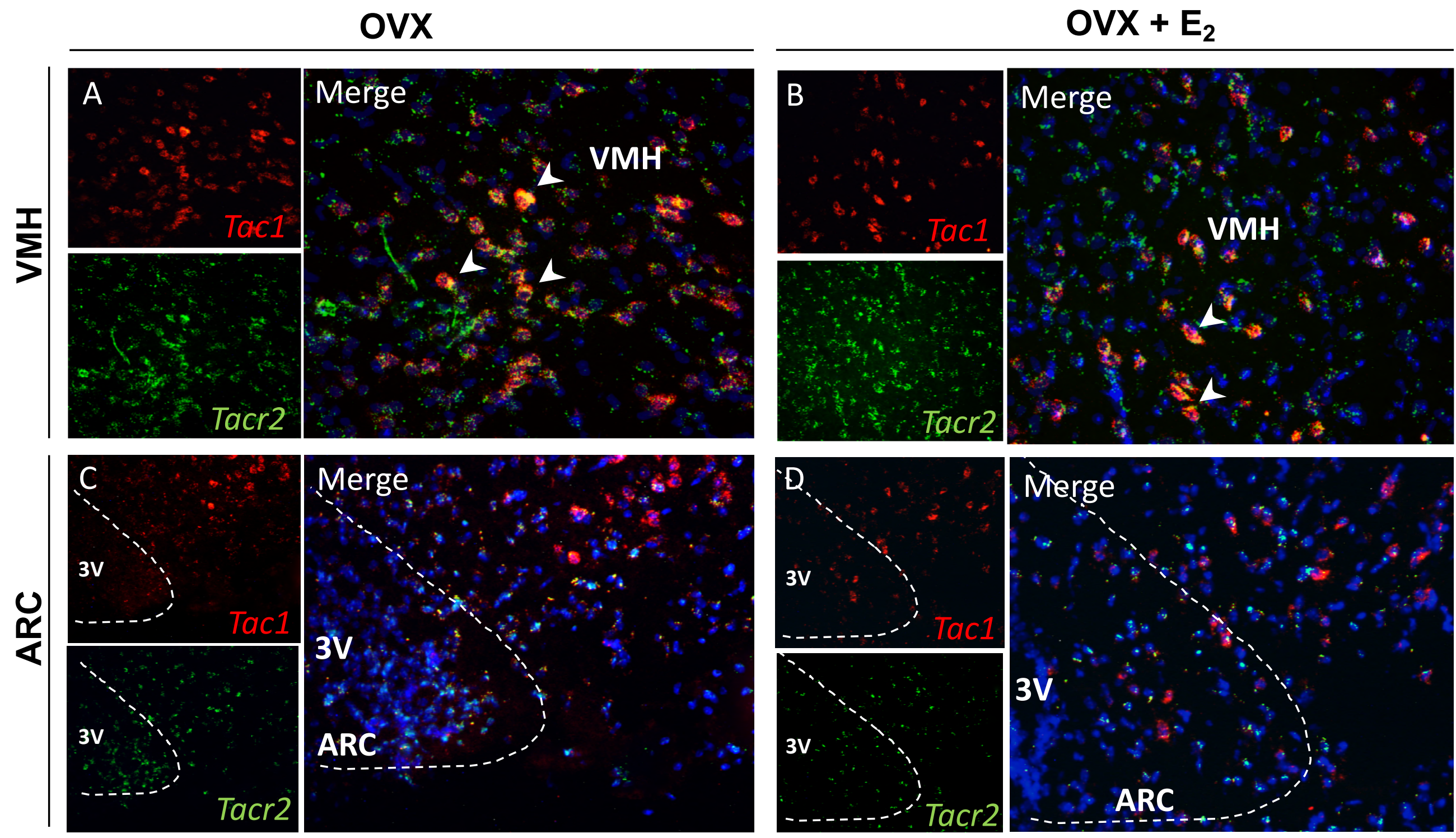

Figure 4 

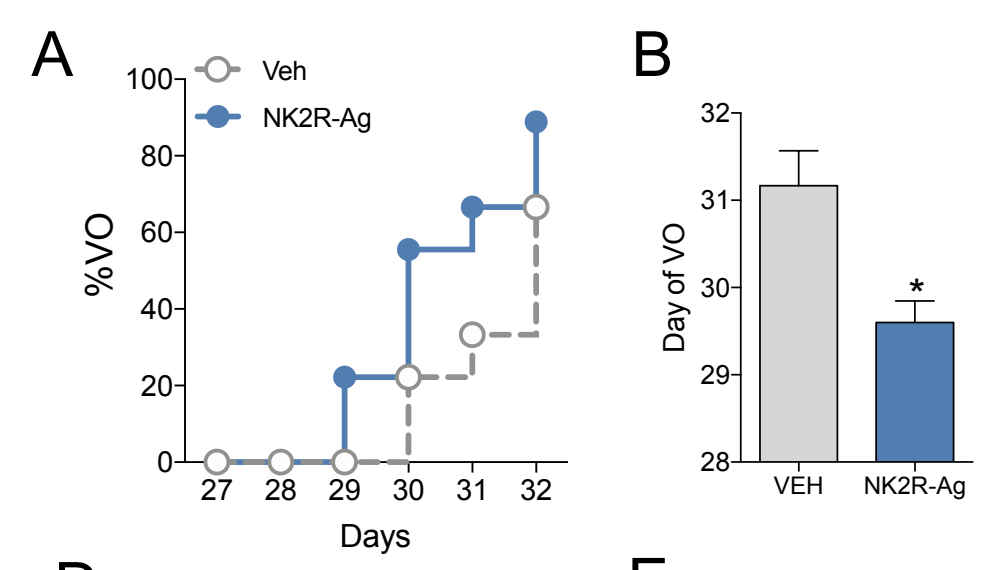

C

D
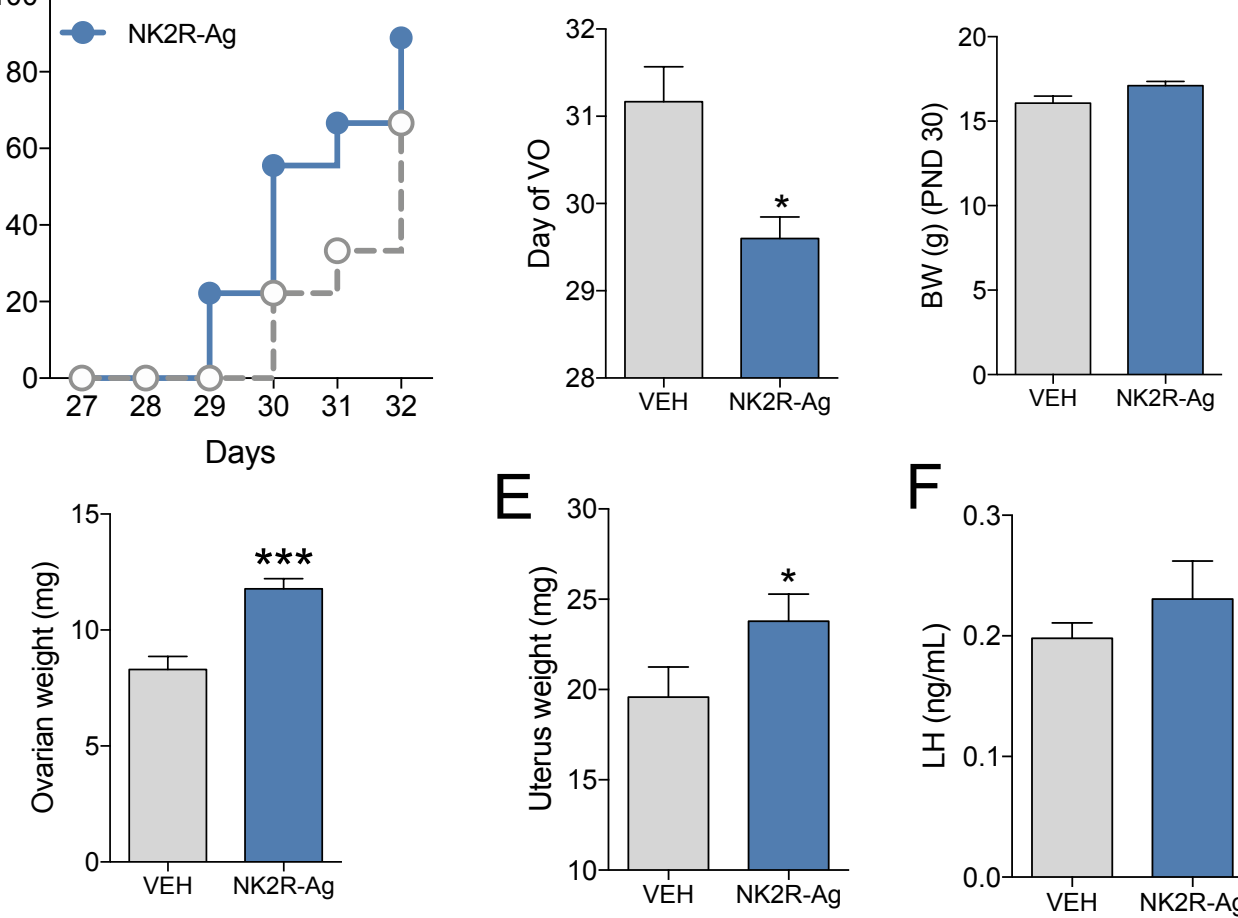

F

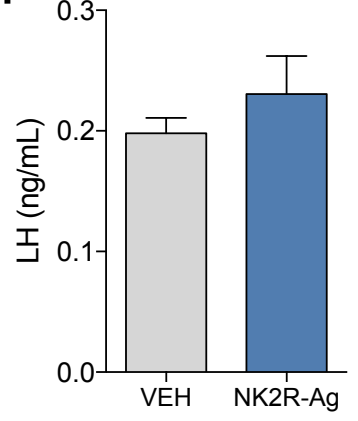

Figure 5 


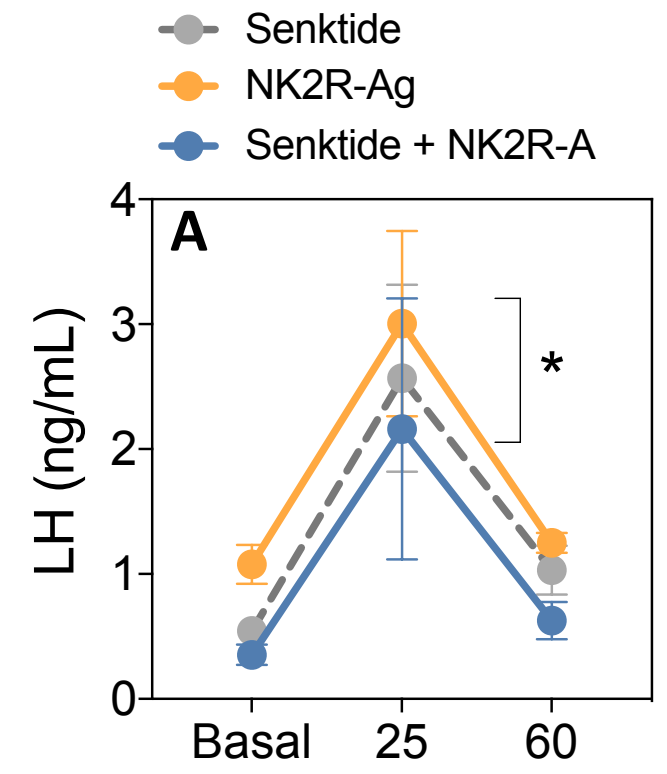

- SB222200 + Veh

SB222200 + NK2R-Ag SB222200 + Senktide

- WT + NK2R-Ag

Tac2 KO + NK2R-Ag
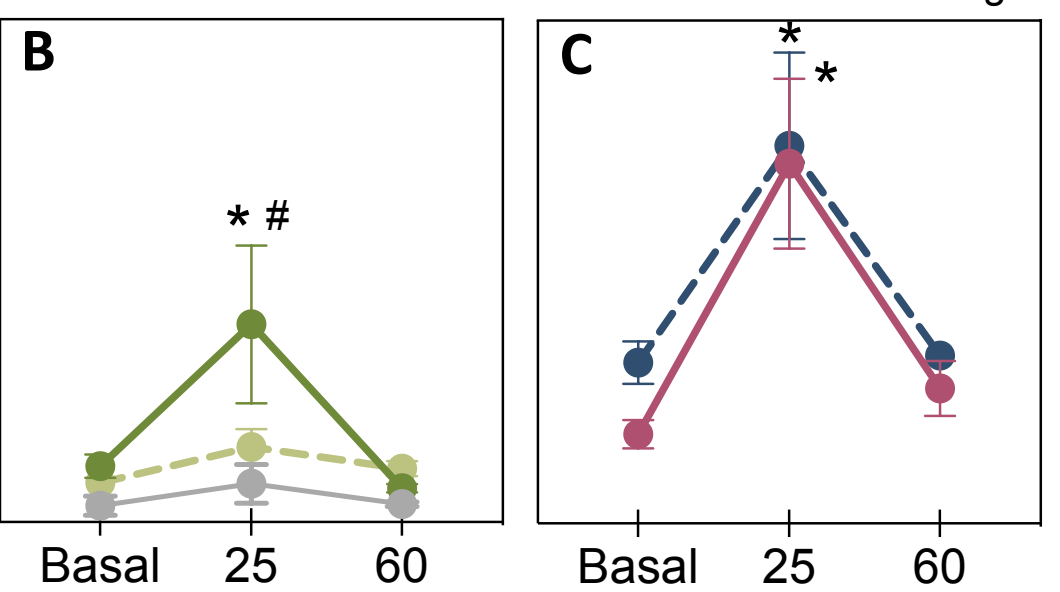

Figure 6 


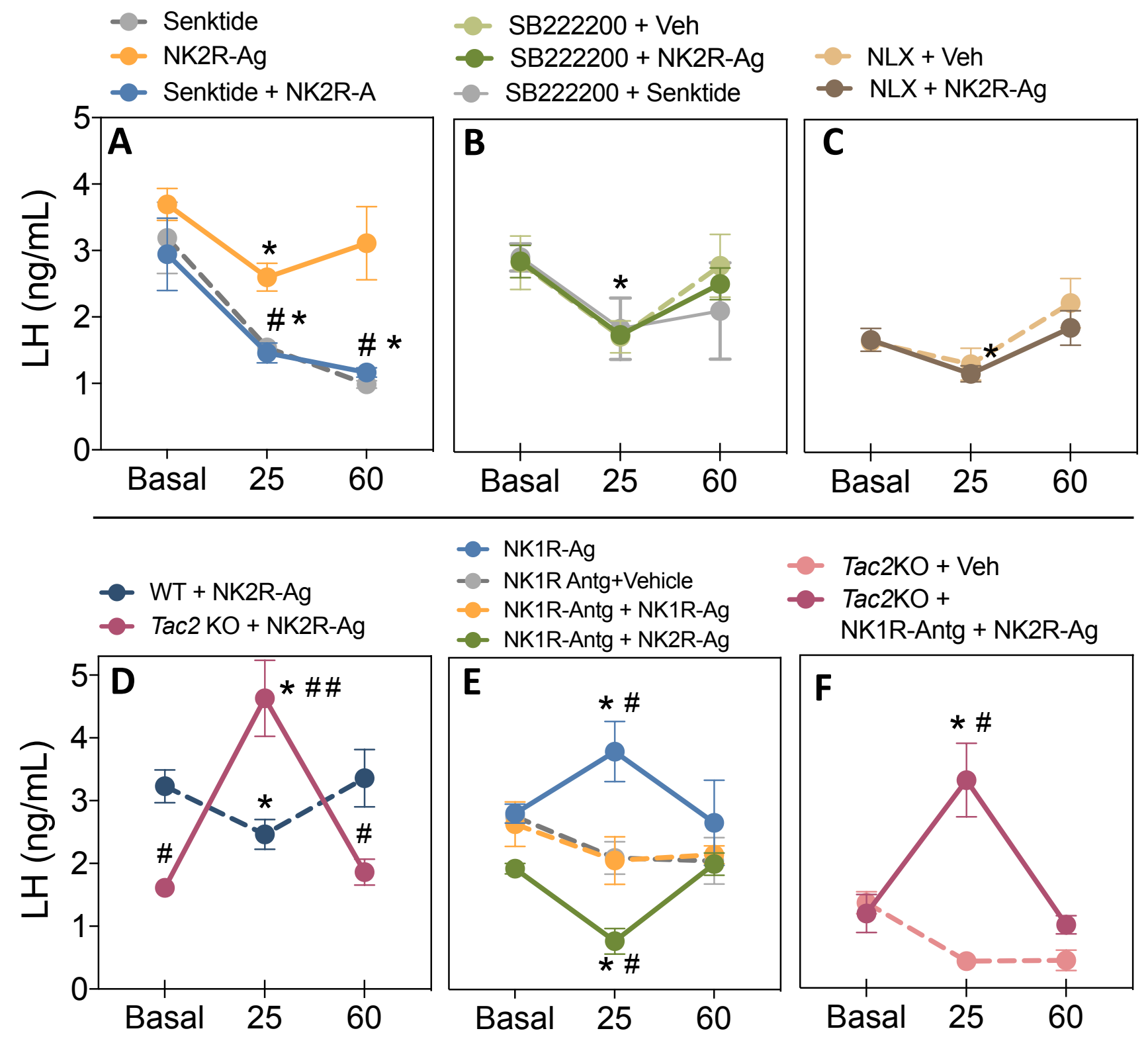

Figure 7 